\title{
Versatility of Chitosan-Based Biomaterials and Their Use as Scaffolds for Tissue Regeneration
}

\author{
José Carlos Viana Ribeiro, ${ }^{1}$ Rodrigo Silveira Vieira, ${ }^{2}$ Iracema Matos Melo, \\ Vilana Maria Adriano Araújo, ${ }^{3}$ and Vilma Lima ${ }^{3}$ \\ ${ }^{1}$ Faculty of Pharmacy, Dentistry and Nursing, Federal University of Ceará, Rua Alexandre Baraúna, No. 949, \\ Rodolfo Teófilo, 60430-160 Fortaleza, CE, Brazil \\ ${ }^{2}$ Department of Chemical Engineering, Federal University of Ceará, Campus do Pici, Bloco 709, Pici, \\ 60455-760 Fortaleza, CE, Brazil \\ ${ }^{3}$ Drug Research and Development Center, Department of Physiology and Pharmacology, Federal University of Ceará, \\ Rua Coronel Nunes de Melo, No. 1000, Rodolfo Teófilo, 60430-275 Fortaleza, CE, Brazil \\ Correspondence should be addressed to Vilma Lima; villima@yahoo.com.br
}

Received 23 December 2016; Revised 10 March 2017; Accepted 3 April 2017; Published 16 April 2017

Academic Editor: Ying Yang

Copyright (C) 2017 José Carlos Viana Ribeiro et al. This is an open access article distributed under the Creative Commons Attribution License, which permits unrestricted use, distribution, and reproduction in any medium, provided the original work is properly cited.

\begin{abstract}
Chitosan is a naturally occurring polysaccharide obtained from chitin, present in abundance in the exoskeletons of crustaceans and insects. It has aroused great interest as a biomaterial for tissue engineering on account of its biocompatibility and biodegradation and its affinity for biomolecules. A significant number of research groups have investigated the application of chitosan as scaffolds for tissue regeneration. However, there is a wide variability in terms of physicochemical characteristics of chitosan used in some studies and its combinations with other biomaterials, making it difficult to compare results and standardize its properties. The current systematic review of literature on the use of chitosan for tissue regeneration consisted of a study of 478 articles in the PubMed database, which resulted, after applying inclusion criteria, in the selection of 61 catalogued, critically analysed works. The results demonstrated the effectiveness of chitosan-based biomaterials in $93.4 \%$ of the studies reviewed, whether or not combined with cells and growth factors, in the regeneration of various types of tissues in animals. However, the absence of clinical studies in humans, the inadequate experimental designs, and the lack of information concerning chitosan's characteristics limit the reproducibility and relevance of studies and the clinical applicability of chitosan.
\end{abstract}

\section{Introduction}

Tissue engineering represents a recent area of multidisciplinary research that applies the knowledge of materials engineering and biology, with the aim of reconstructing or regenerating damaged biological tissue in clinical/pathological situations such as lesions, infections, traumas, and sequelae resulting from tumors or systemic disorders. To this end, it was sought to develop biological substitutes capable of restoring, maintaining, or improving organ and tissue function. Tissue engineering approaches generally involve using a combination of cells, bioactive molecules, and biomaterials. The cells are responsible for the synthesis of the matrix of new tissue. Bioactive molecules, such as cytokines and growth factors, promote cell proliferation, differentiation, and migration. Biomaterials act as a scaffold for the new tissue, providing an environment that favors cell growth and differentiation $[1,2]$.

All tissue is basically made up of an extracellular matrix (ECM) and cell components. The ECM is the structure upon which the cells establish and organize themselves, providing the environment and architecture specific for cell growth and proliferation, functioning as a reservoir of water, nutrients, and growth factors essential to cells $[3,4]$. In this regard, when the regeneration of tissue is desired, the presence is required of a structure that acts as a temporary matrix, mimicking the ECM, allowing cell proliferation and tissue synthesis, until regeneration is complete $[5,6]$. This structure, the scaffold, 


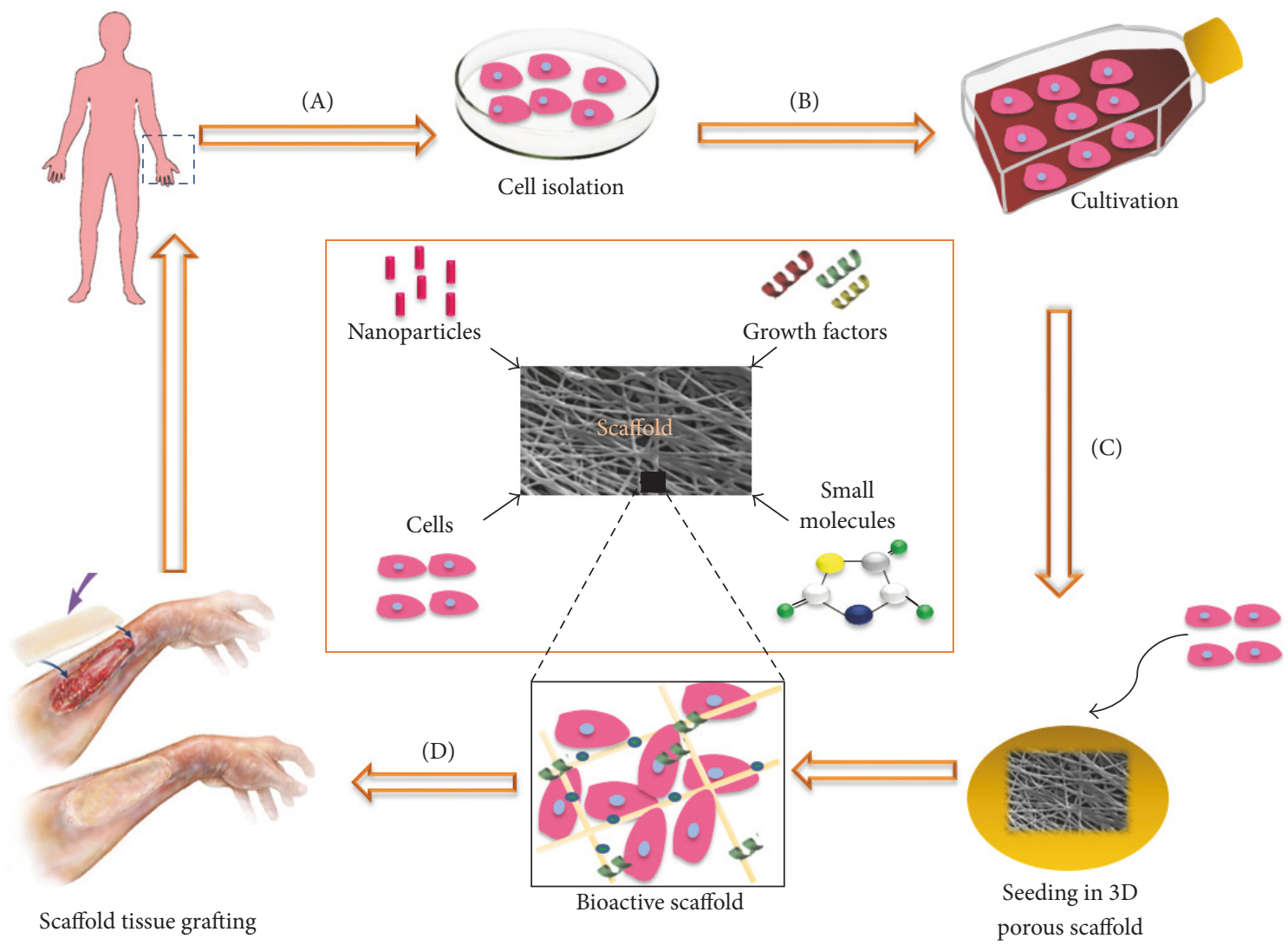

FIGURE 1: Diagram of the concept of tissue engineering. (A) Cells are isolated from humans or animals, (B) cultivated in vitro, and (C) incorporated into a three-dimensional porous biomaterial (scaffold), together with growth factors, small molecules, and/or micro/nanoparticles. (D) The bioactive scaffold is then grafted onto a tissue lesion, promoting its regeneration. Adapted from Dvir et al. 2011 [12] and Lanza et al. 2014 [2].

may be defined as a porous, three-dimensional, solid biomaterial that acts as a temporary ECM during tissue regeneration [7]. The biomaterials used as scaffolds in tissue regeneration are of fundamental importance and may determine the success or failure of any tissue engineering approach [8, 9]. Like the ECM, scaffolds must promote vascularization and provide a three-dimensional infrastructure that permits new tissue to form. Also, they must be able to act as a carrier of biologically relevant molecules and, ideally, modulate their biological responses and the regeneration process (Figure 1). Thus, the use of a biomaterial as a scaffold for tissue engineering assumes that it has certain characteristics that make it similar to the extracellular matrix [9-12].

In tissue engineering, the scaffold must have a temporary structure that undergoes gradual biodegradation over a period of time consistent with the speed of new tissue formation, allowing the regenerated tissue to replace it. To this end, it is necessary to possess certain essential characteristics, such as biocompatibility, biodegradability, and mechanical performance and surface properties such as porosity, which favor cell adhesion $[7,10]$. The materials most commonly used for tissue regeneration include calcium phosphate ceramics like hydroxyapatite (HA) and beta-tricalcium phosphate $(\beta$-TCP), synthetic polymers such as polyglycolic acid (PGA) and poly(lactic-co-glycolic) acid (PLGA), and naturally occurring biodegradable polymers such as collagen, hyaluronic acid, silk fibroin, gelatin, and chitosan [5, 13-15].

Chitosan is a polysaccharide obtained from abundant sources in nature and has been regarded as having great potential for application as a biomaterial for tissue regeneration. It is obtained through the deacetylation of chitin, a polymer found in the exoskeleton of crustaceans, mollusks, and insects and on the cell walls of fungi [16]. Chitosan (CS) has a chemical structure with a linear chain composed of units of $D$-glucosamine and $N$-acetyl-glucosamine joined together via $\beta$ (1-4) glycosidic bonds (Figure 2). In this structure, there are three reactive functional groups: one amine $\left(\mathrm{NH}_{2}\right)$ and two hydroxylic groups $(\mathrm{OH})$. These groupings, particularly the amine, give $\mathrm{CS}$ a cationic nature due to the protonation of amino groups $\left(\mathrm{NH}_{3}+\right)$ in acidic medium. This peculiar cationic nature gives CS a great affinity for anionic biomolecules, such as sialic acid, sulfonic acid, and the glycosaminoglycans (GAGs) abundantly present in mucous secretions and extracellular matrix $[17,18]$. In fact, CS is considered to be the only natural polysaccharide with this characteristic [19]. By way of ionic interactions, CS has the capacity to bond with mucous tissue, called mucoadhesiveness [10, 20-22]. This property is of great interest to tissue engineering as the possibility of using a scaffold that interacts with the GAGs and tissue's proteoglycans may facilitate the incorporation of 


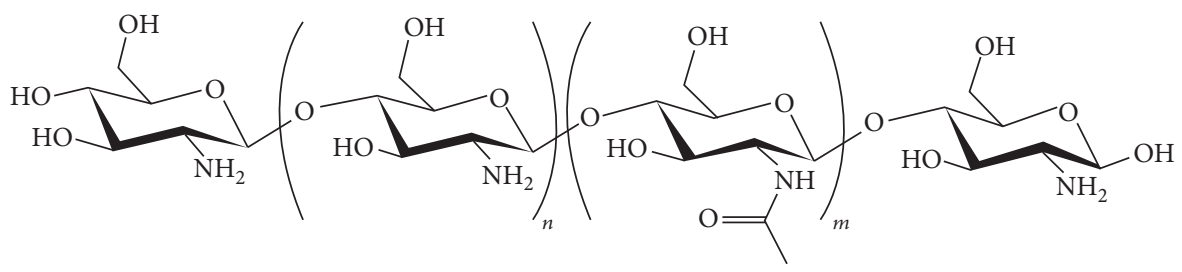

Figure 2: Chemical structure of chitin/chitosan. The index $n$ represents the number of repeat units of glucosamine in the chain and $m$ the number of repeat units of acetyl-glucosamine in the chain $(n+m$ indicating the degree of polymerization and $m / n+m$ being the degree of acetylation). When $n$ is more than $50 \%$, the polymer is called chitosan. Content of $\mathrm{NH}_{2}$ increases its reactivity $[16,25]$.

cytokines and tissue growth factors, as a large number of these factors have an affinity with GAGs $[23,24]$.

The singular physicochemical and biological characteristics of CS have prompted numerous studies investigating its application as a scaffold for tissue regeneration [26-31]. Biocompatibility, biodegradability, mucoadhesiveness, absence of toxicity, capacity to form three-dimensional porous structures, ease of handling, and low cost are just some of the benefits mentioned by the authors, which make CS a suitable biomaterial with great potential for application in tissue engineering. Moreover, the reactivity of CS also makes it possible to modify its structure through the substitution of its functional groups, which allows it to be combined with other synthetic or natural polymers, forming the so-called polymer blends, or composites with calcium and phosphate ceramics. These modifications enable the characteristics of CS to be modulated, such as solubility, biodegradability, and mechanical performance, depending upon the type of tissue to be regenerated, which makes it an extremely versatile biomaterial for application in tissue engineering [17, 32-36].

There is, however, a great diversity in the characteristics of CS used in the studies for tissue regeneration, either for the structure of the scaffolds, such as membranes, sponges, films, and nanofibrils, or for the physicochemical parameters of chitosan. The degree of acetylation (DA) and molecular weight (MW), for instance, are the two major chemical properties of CS and influence other physicochemical and biological characteristics, like solubility, crystallinity, mechanical performance, biocompatibility, and biodegradation [19, 37-40]. The lack of standardization in the studies, particularly with regard to the physicochemical characteristics of CS, makes it difficult to establish a consensus as to its applicability as a scaffold for tissue engineering. The present study proposes a systematic review of the literature on the use of chitosan in tissue engineering, with a critical approach to studies on animals and humans, with the aim of establishing a relationship between the methodologies used and results obtained in tissue regeneration, so as to make a contribution to the understanding of the application of this material and to demonstrate its potential use.

\section{Methodology}

For this systematic review, a search was conducted of the PubMed electronic database, through the US National Library of Medicine portal (https://www.ncbi.nlm.nih.gov/ pubmed/) by two independent researchers, in accordance

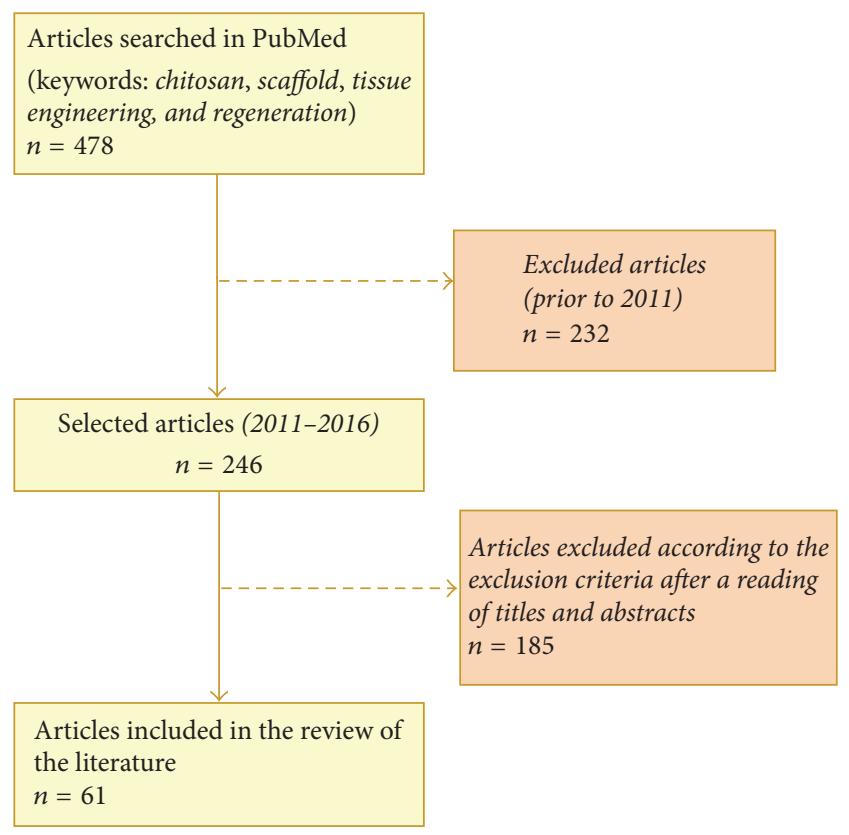

FIGURE 3: Flowchart of the research study and selection of articles for bibliographical review.

with the selection criteria. For the search, the following keywords were employed: chitosan, scaffold, tissue engineering, and regeneration. The initial study produced 478 articles. The search was restricted to the last five years and only preclinical studies (with animals) or clinical studies (humans) were used, resulting in 246 articles. After a critical reading of the titles, abstracts, and, where necessary, the articles' methodology, only articles published in English were included. The following exclusion criteria were then applied:

(i) Literature reviews

(ii) Case studies

(iii) Studies in which CS was not used to evaluate tissue regeneration

(iv) Abstracts or studies where the full content was not accessible

The final selection resulted in 61 articles that were studied, catalogued, and grouped in tables, according to the type of tissues that was involved. A flowchart of the bibliographic research is displayed in Figure 3. 


\section{Results}

The selected articles were analysed and the results are shown in Tables 1-5, which list, according to the type of tissues involved, most relevant information such as the scaffold characteristics, main physicochemical properties of CS (when available), combinations with other polymers, incorporation of growth factors and/or cells, the in vitro and in vivo methodology evaluated, the main results in terms of tissue regeneration, and the authors' major conclusions.

Of the 61 studies selected, 60 consisted of preclinical assays using rats (51.6\%), rabbits (26.6\%), mice (13.3\%), dogs $(5 \%)$, and guinea pigs (3.5\%). Only one article demonstrated the effects of CS on human tissue [68].

As far as the analysed tissue types are concerned, $44.3 \%$ investigated the action of CS on bone tissue $[8,28,41-52,54-$ $62,80,85,86]$, osteochondral regeneration $[80,85,86]$, and bone and vascular [53] or bone and muscular tissues [56]. Moreover, $19.7 \%$ of the studies evaluated CS in the regeneration of skin [24, 27, 29, 63-71], 14.7\% in nervous tissue [30, $72-79], 11.5 \%$ in cartilage [ $32,81-84,87,88]$, and $3.3 \%$ in periodontal $[33,90]$ structures. The remaining studies involved regeneration of colorectal [26], mammary [89], tympanic membrane [31], and vascular [34] tissues (1.6\% each).

As for the characteristics of the scaffolds, the majority of studies involved CS combined with other biomaterials $(85.25 \%)$, including HA (16\%), collagen (14\%), gelatin (10\%), silk fibroin (10\%), PLGA (8\%), multiple combinations between them (20\%), or forming other polymer blends (22\%). Scaffolds of natural CS were used in $14.75 \%$ of the studies [26, 28, 31, 33, 59, 64, 74, 75, 79]. The physicochemical characteristics of CS varied greatly. The molecular weight ranged from 22 [74] to 1,800 [73] kilodaltons $(\mathrm{kDa})$, while the degree of acetylation ranged from $2 \%$ [54] to $40 \%$ [81]. In almost one-half of the studies reviewed (47.5\%), the molecular weight and degree of acetylation of the chitosans used were not specified. When these parameters were mentioned, $46.9 \%$ of the chitosans exhibited low molecular weight (up to $150 \mathrm{kDa}$ ), $37.5 \%$ were of average molecular weight (150 to $700 \mathrm{kDa}$ ), and $12.6 \%$ had a high molecular weight (in excess of $700 \mathrm{kDa}$ ). As for the macrostructure of the scaffolds, these were primarily used in the form of sponges $(24.6 \%)$, membranes (19.6\%), conduits or tubules (13.1\%), or even as nanofibrils, hydrogels, microspheres, powder, and paste (11.4\%) or were unspecified (31.3\%). In $63.9 \%$ of the studies, there was an incorporation into the scaffolds of bioactive molecules such as growth factors, genetic factors, peptides, extracellular matrix, or cell components such as stem cells and other cells related to tissue involved in regeneration, or even drugs.

As far as the study outline is concerned, $75.4 \%$ used in vitro and in vivo assay methodologies in their investigation of scaffold activities with CS, while in $24.6 \%$ of studies only in vivo assays were performed. The in vitro analyses consisted of tests on the cytocompatibility of the scaffolds in cell cultures, evaluating cell adhesion, proliferation, viability, and differentiation. The in vivo assays investigated the effects of scaffolds on tissue regeneration and/or their biocompatibility through macroscopic, radiographic, tomographic, and histological analyses and biomolecular tests such as PCR and immunoassays to detect specific tissue markers involved in regeneration. With regard to the use of comparison groups, $59 \%$ of the studies used negative control groups, and $32.8 \%$ did not use negative control groups, while in $8.2 \%$ of studies the control was not specified in the methodology. In $11.5 \%$ of studies, both positive and negative controls were employed, while in $8.2 \%$ only positive controls were employed. As for sample size, $21.3 \%$ of studies used, in their in vivo assays, samples where $n$ was less than 4 sample units; $36.1 \%$ had a value of $n$ between 4 and 6; in 13.1\% $n$ was between 8 and 10 and $13.1 \%$ had $n$ greater than 10 . The sample size was not specified in the methodology in $16.4 \%$ of the studies reviewed.

The interrelationship between the scaffolds and their effects on tissue regeneration reveals that, in $93.4 \%$ of the studies, scaffolds using CS promoted in vivo or ex vivo tissue regeneration. Only $6.6 \%$ of the studies $[27,41,71,85]$ showed no evidence of the scaffolds having a positive influence on tissue regeneration.

\section{Discussion}

Regenerative medicine has been highlighted as one of the most promising fields of scientific research towards which the most recent advances in biological sciences are converging, such as tissue engineering, stem-cell technology, and genetic therapy. The progress achieved in the area of tissue engineering is due, for the most part, to the huge volume of studies using biomaterials that offer potential for regeneration of almost all tissues and organs in the human body. In this context, chitosan has received a great attention from the scientific research literature. Its favorable characteristics as a biomaterial, such as biocompatibility, biodegradability, and, above all, chemical affinity with biological molecules, make it an attractive material for tissue regeneration applications. Also, its chemical reactivity allows its properties to be modulated, making it an extremely versatile material $[7,19]$.

In the present review, the versatility of CS applications can be observed. It was used in scaffolds for the regeneration of bone, cartilage, skin, nerve, periodontal, vascular, colorectal, mammary, and tympanic membrane tissues. However, though CS is considered to be a biomaterial of great potential for over a decade [16], it is somewhat surprising that none of the studies reviewed in this work has applied CS in clinical trials on human beings. In fact, in the only study where CS was evaluated on human tissue, this was implanted in cutaneous tissue ex vivo or, in other words, removed from individuals who had been subjected to breast or abdomen reduction surgery [68]. This paucity of clinical studies may be explained by researchers' difficulties in obtaining ethical research approval for the use of this material, as there are no regulations for the use of CS as a biomaterial for human tissue regeneration. In the USA, the regulatory agency FDA only approves the use of CS in human beings for the bandaging of skin wounds or hemostatic dressings, while, in other countries such as Japan, Italy, Finland and Brazil, its use is approved as a food supplement and in the cosmetics industry $[17,25,35]$.

Most of CS's versatility may be explained by the numerous possibilities of modification in its chemical structure through 


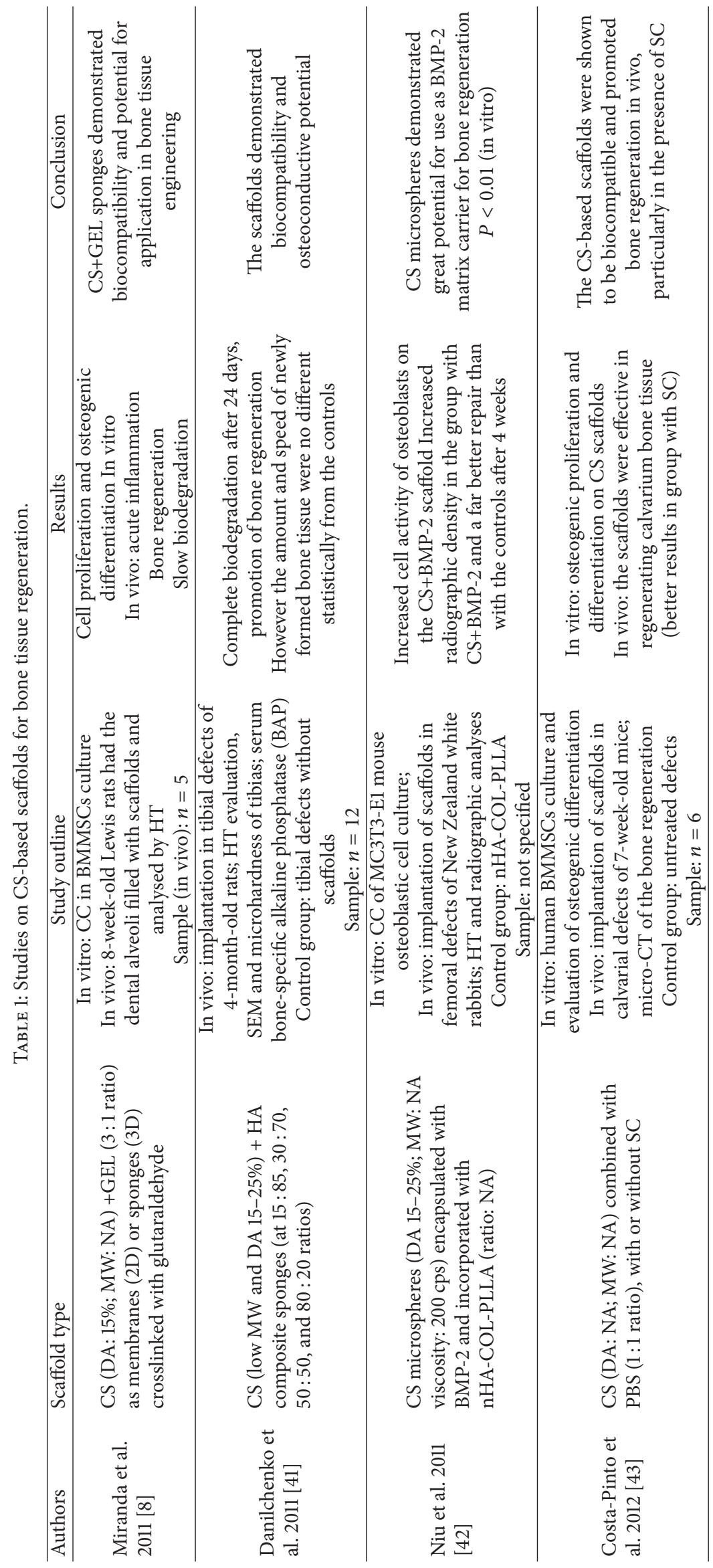




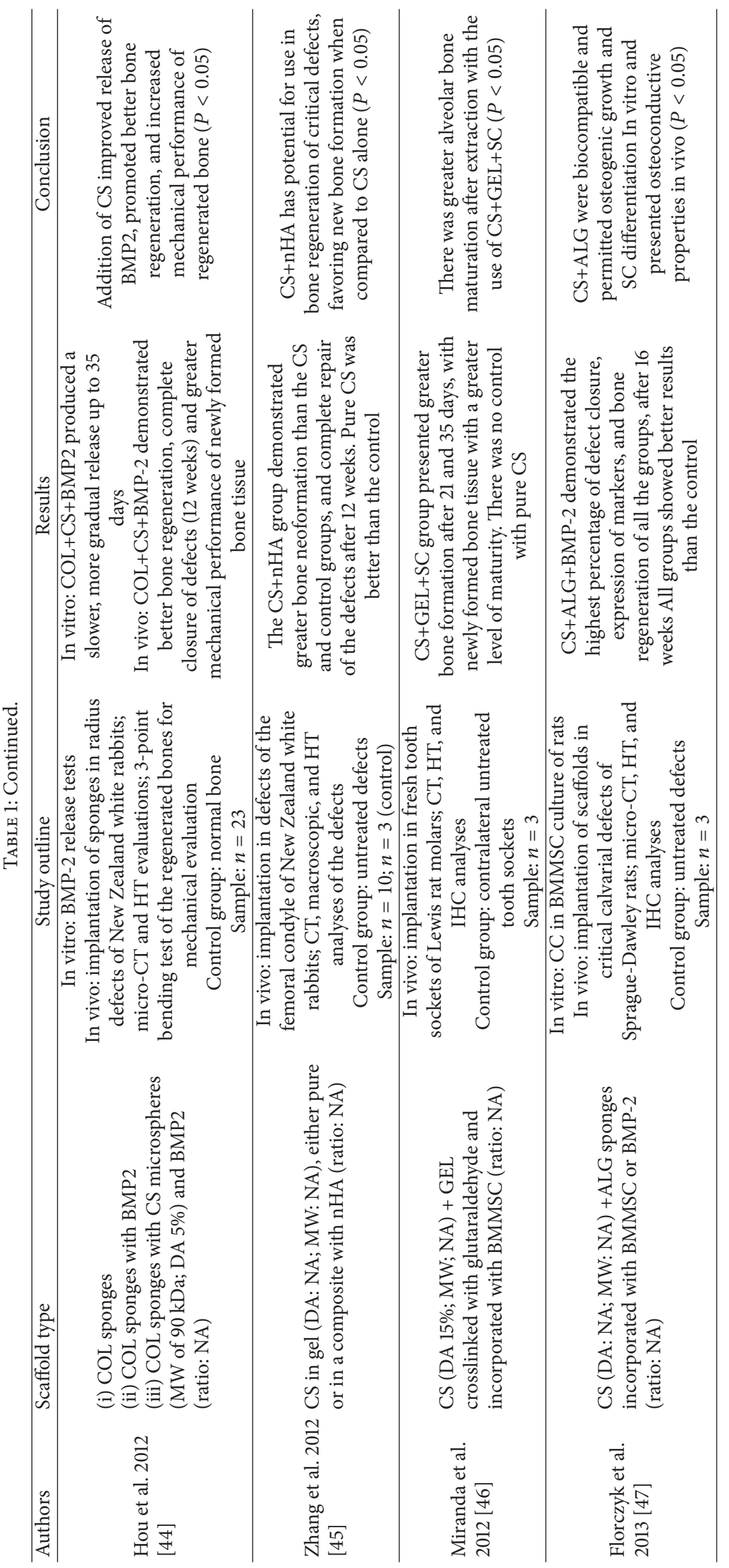




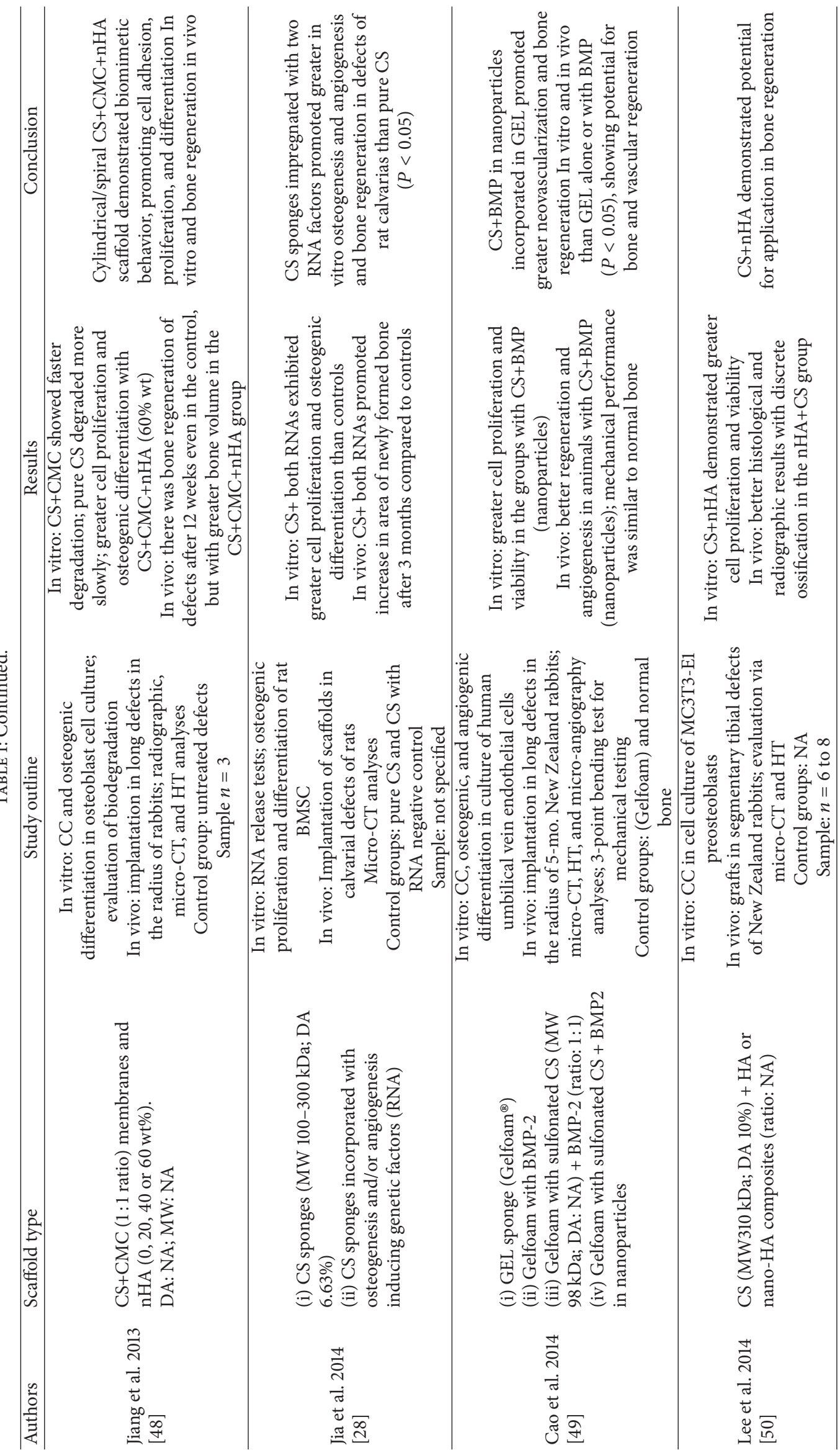




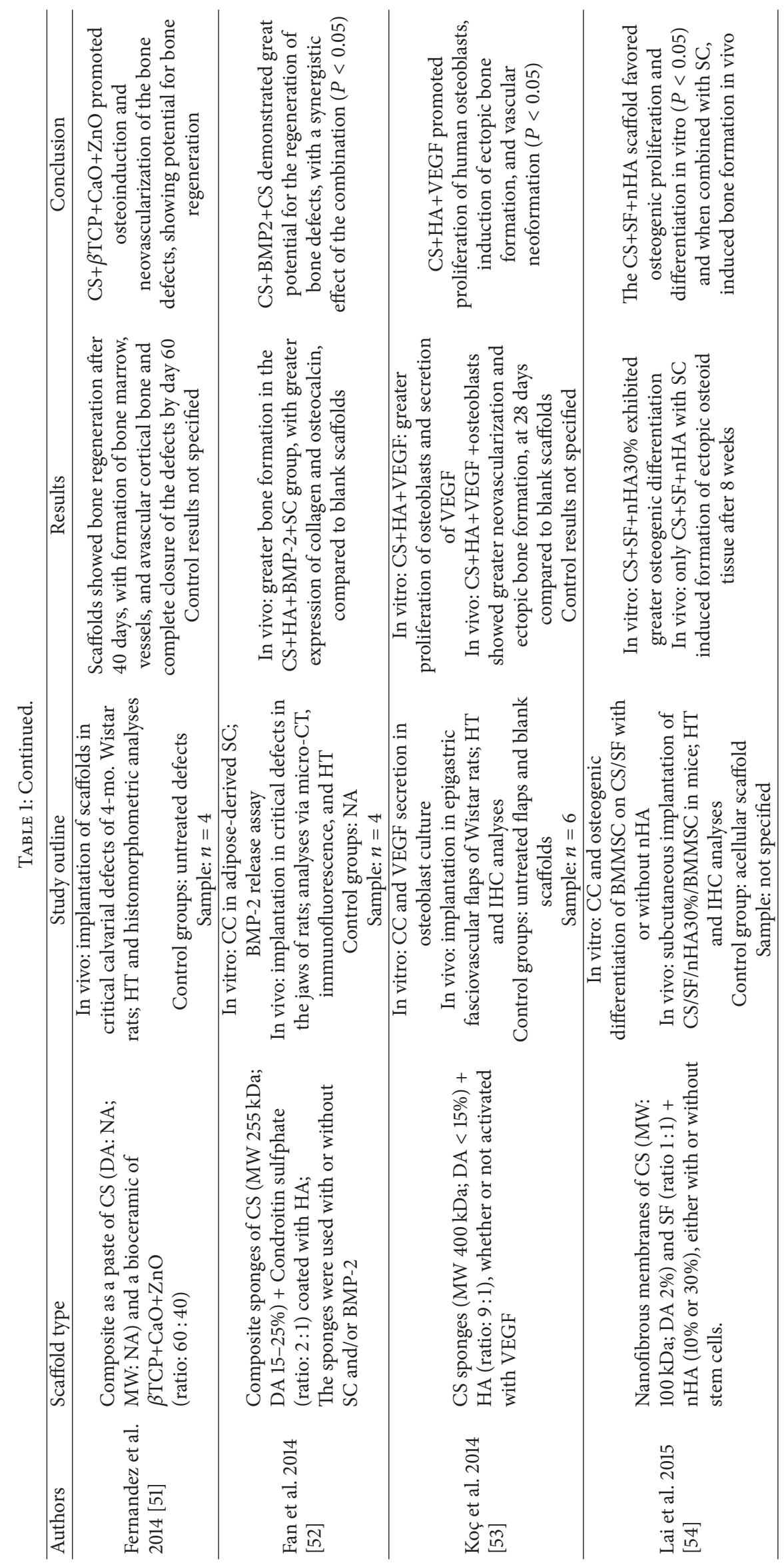




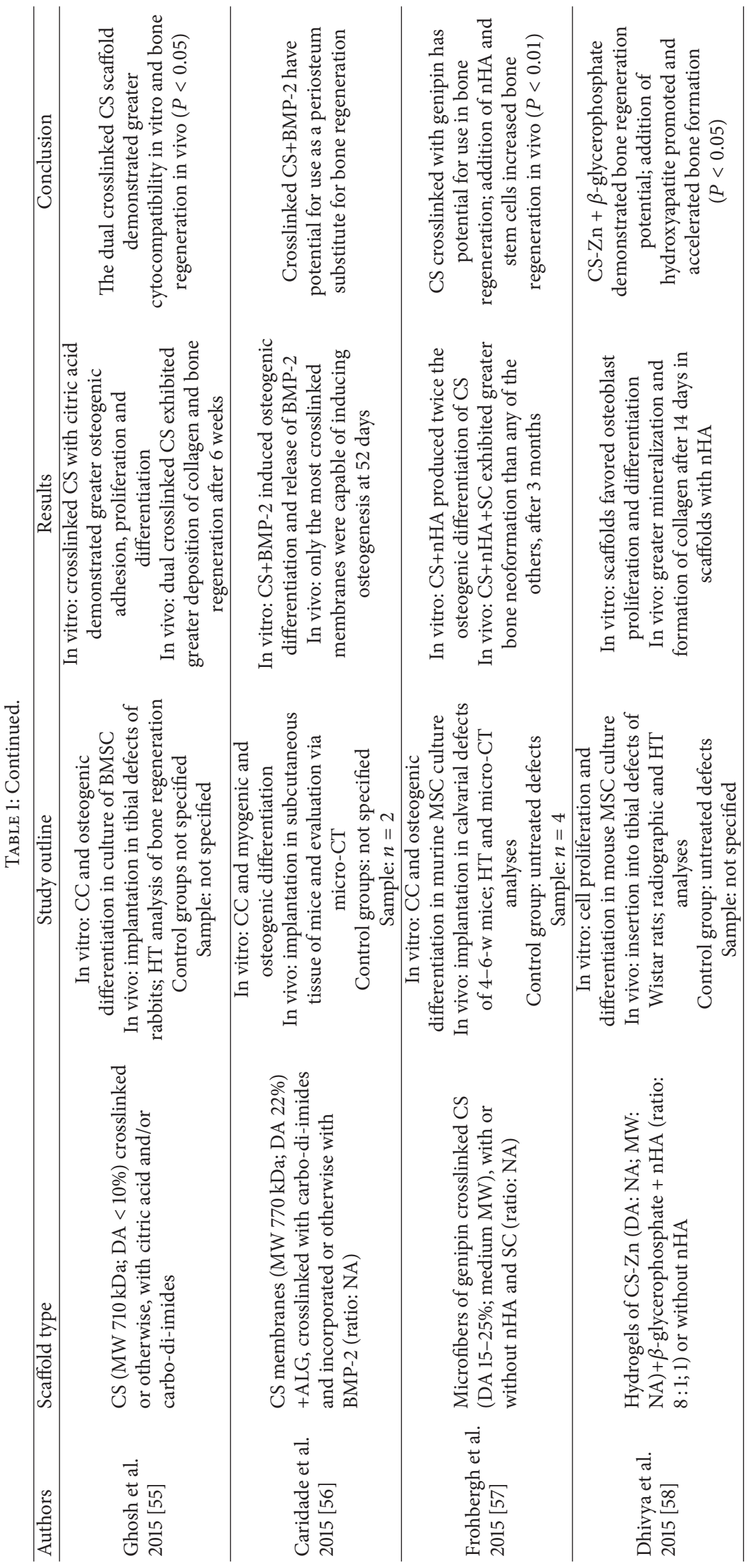




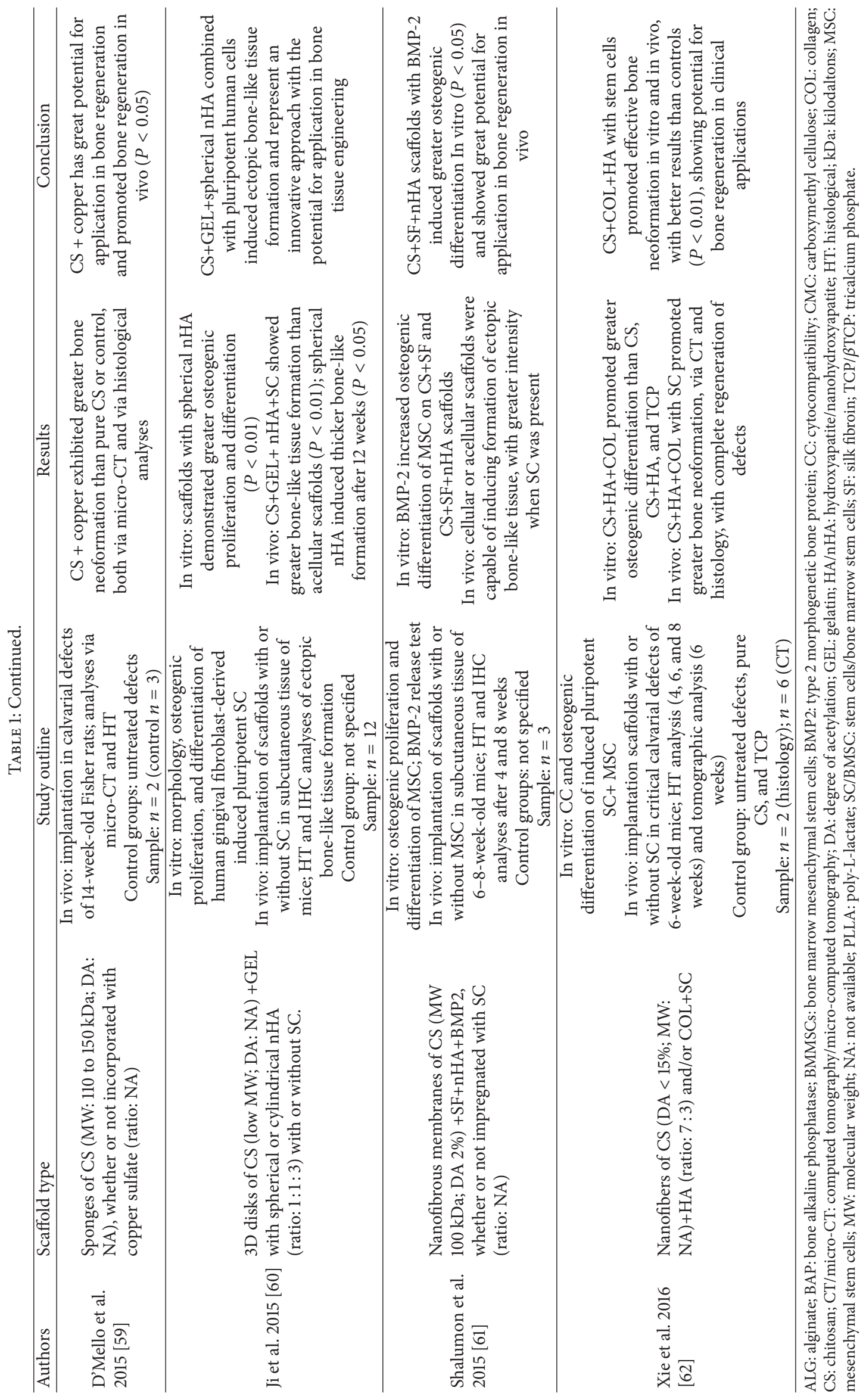




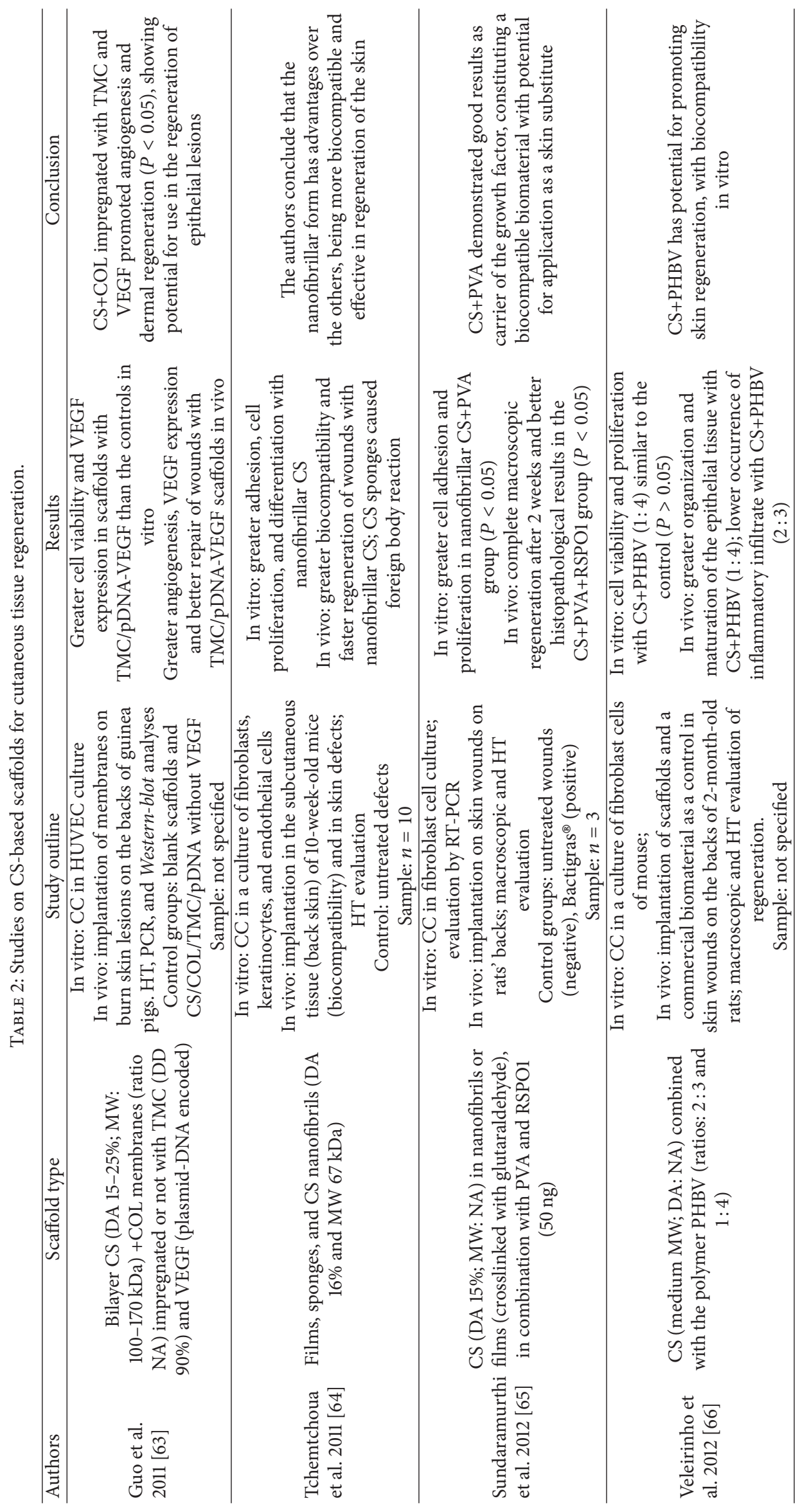




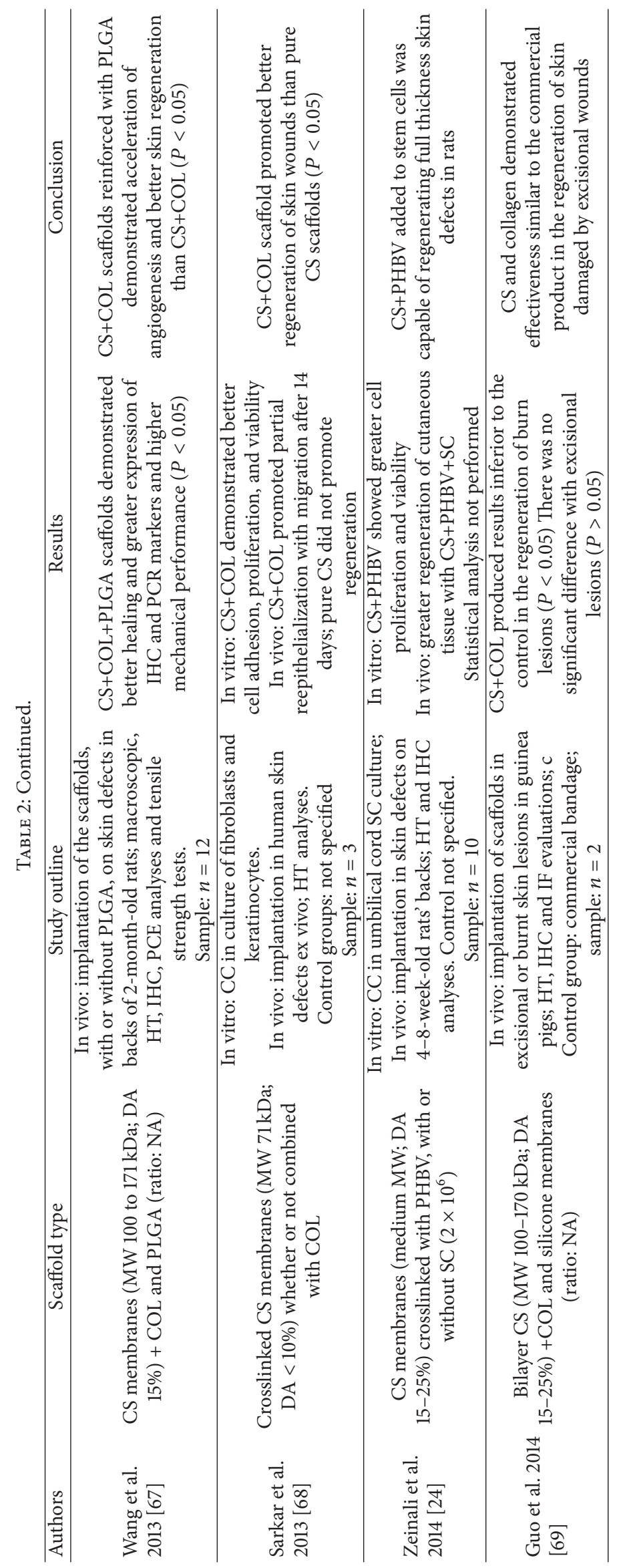




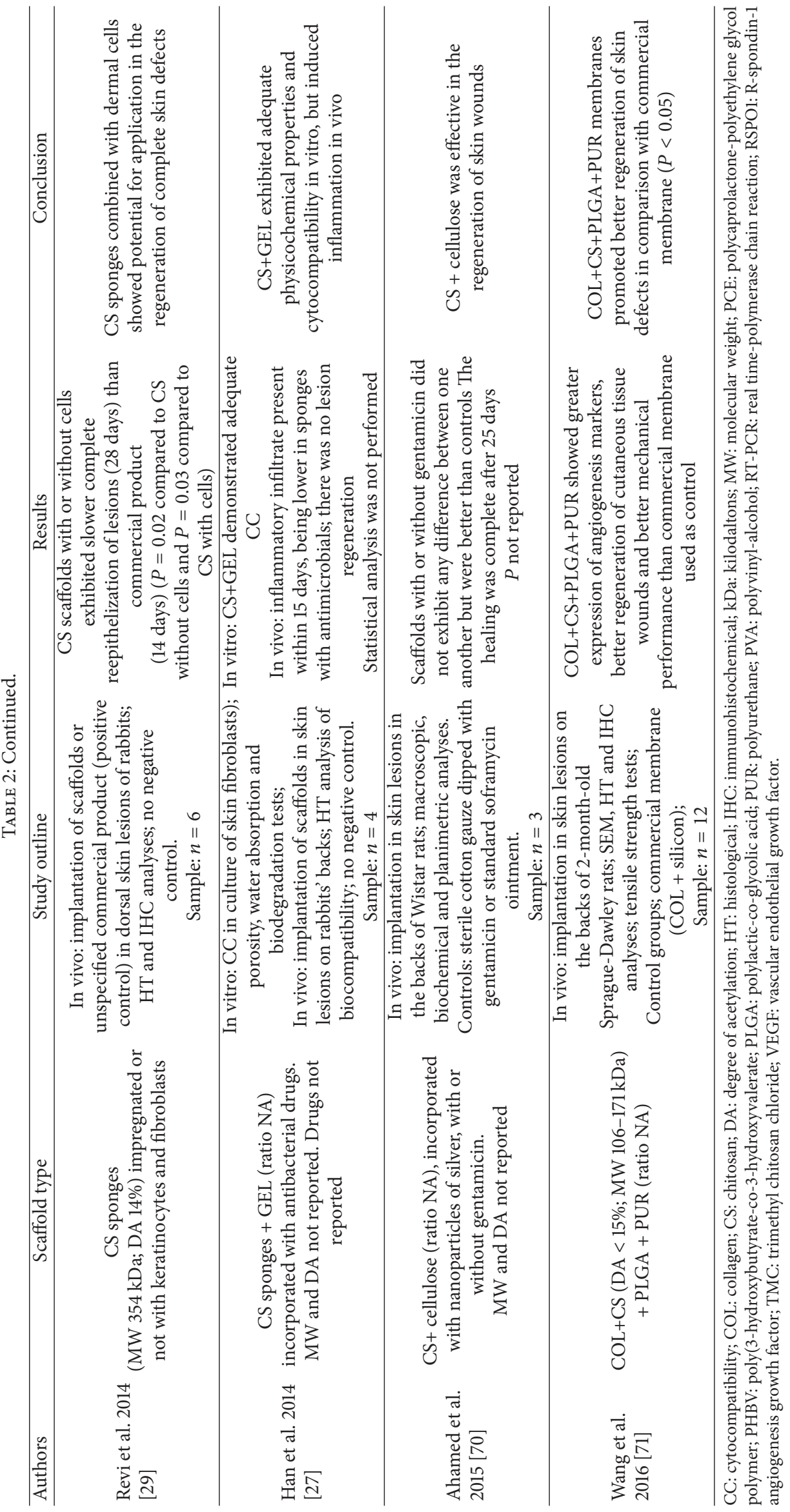




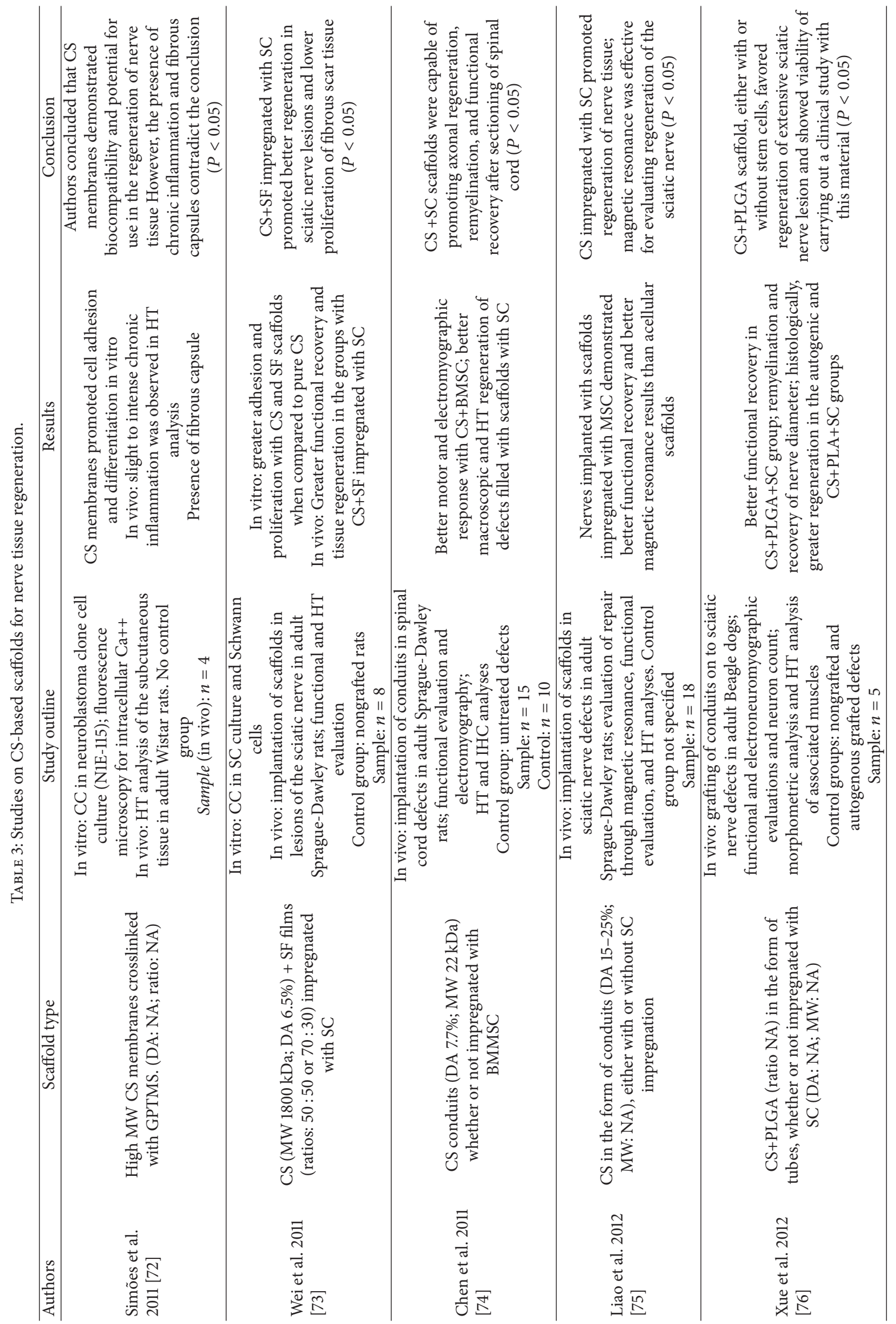




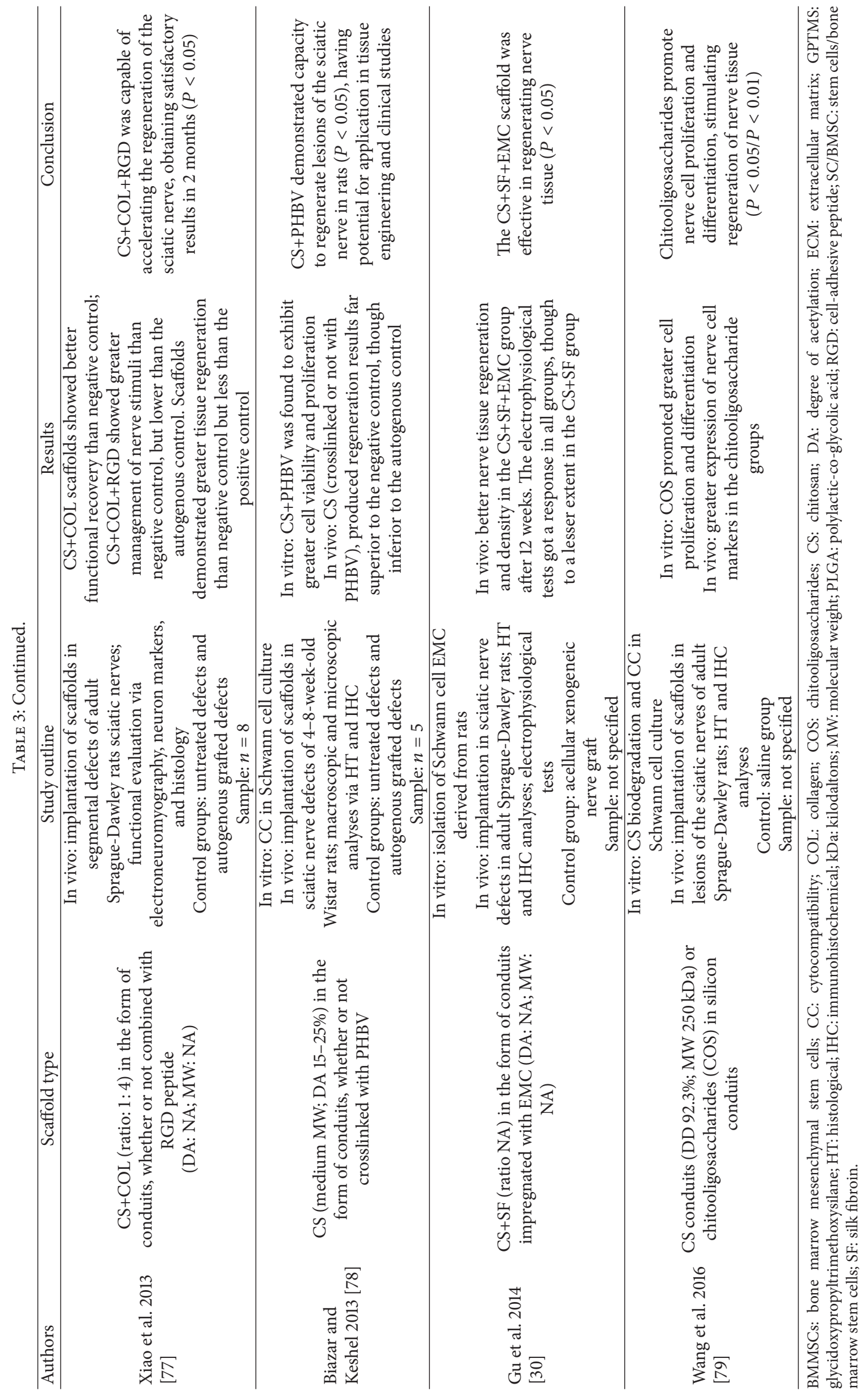




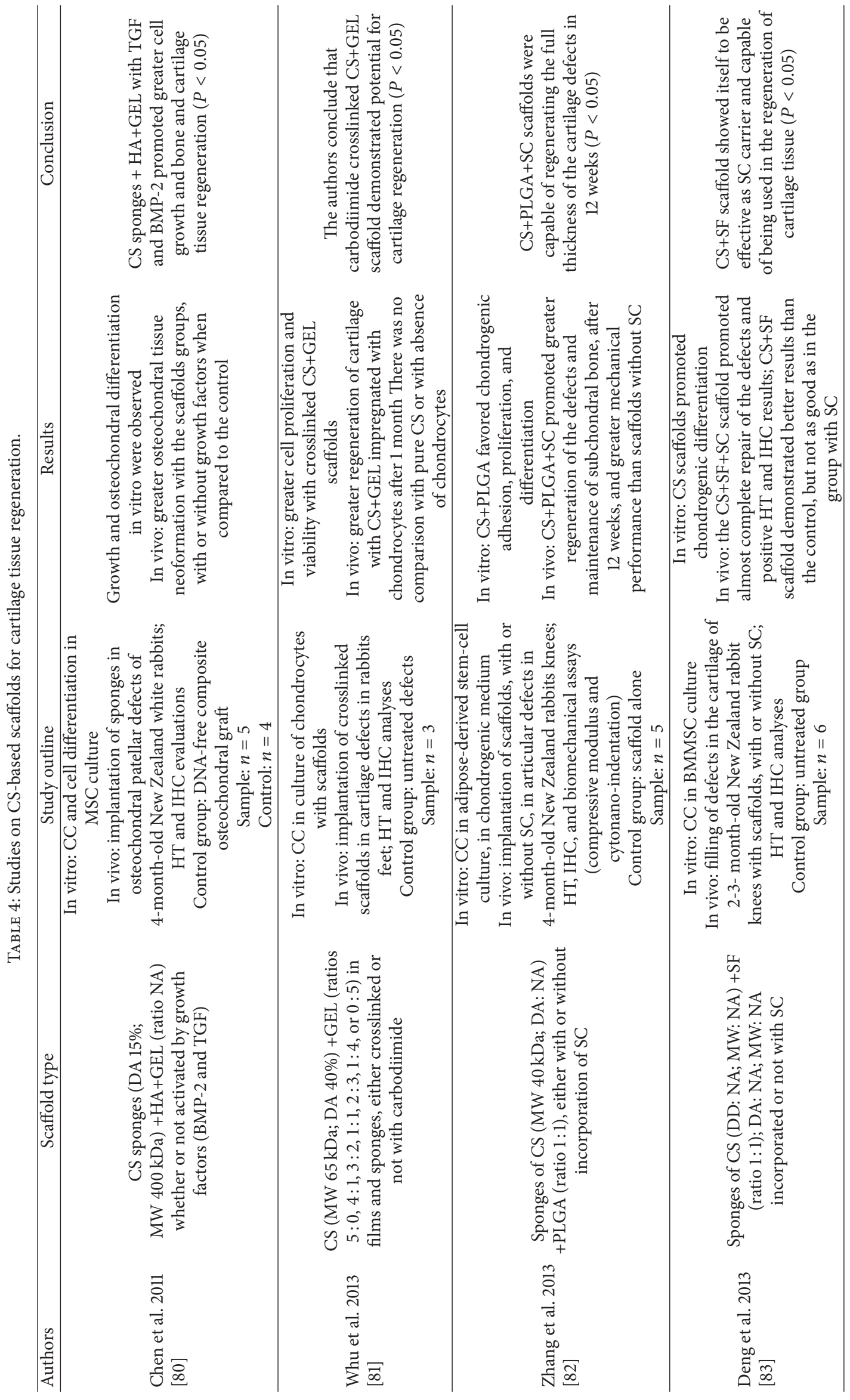




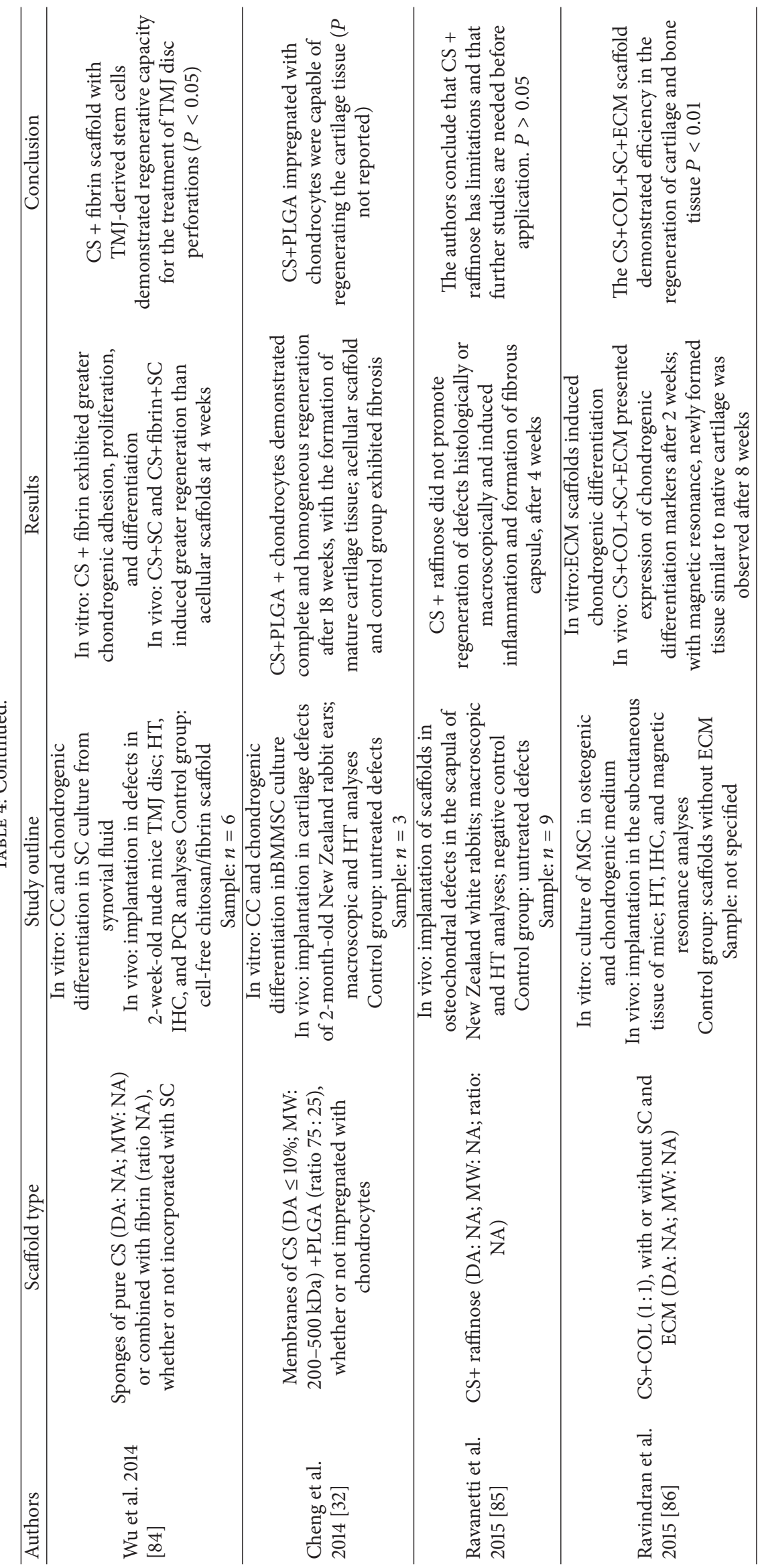




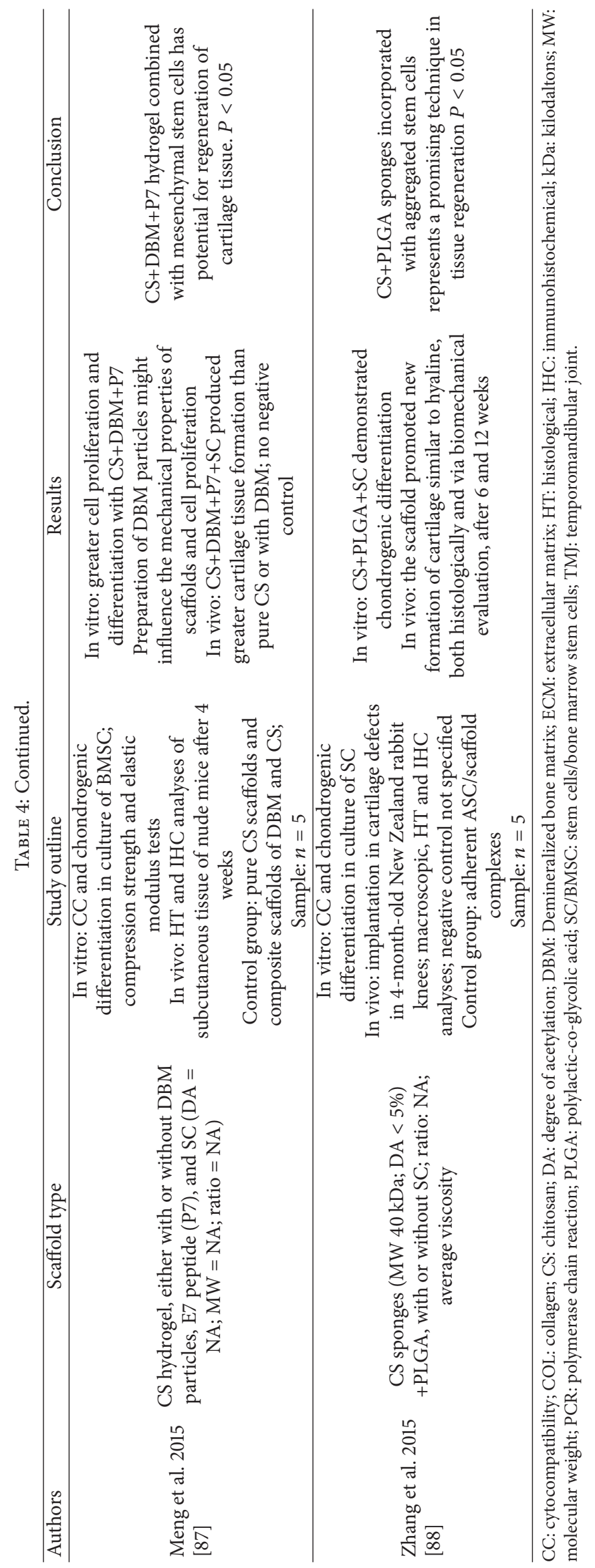




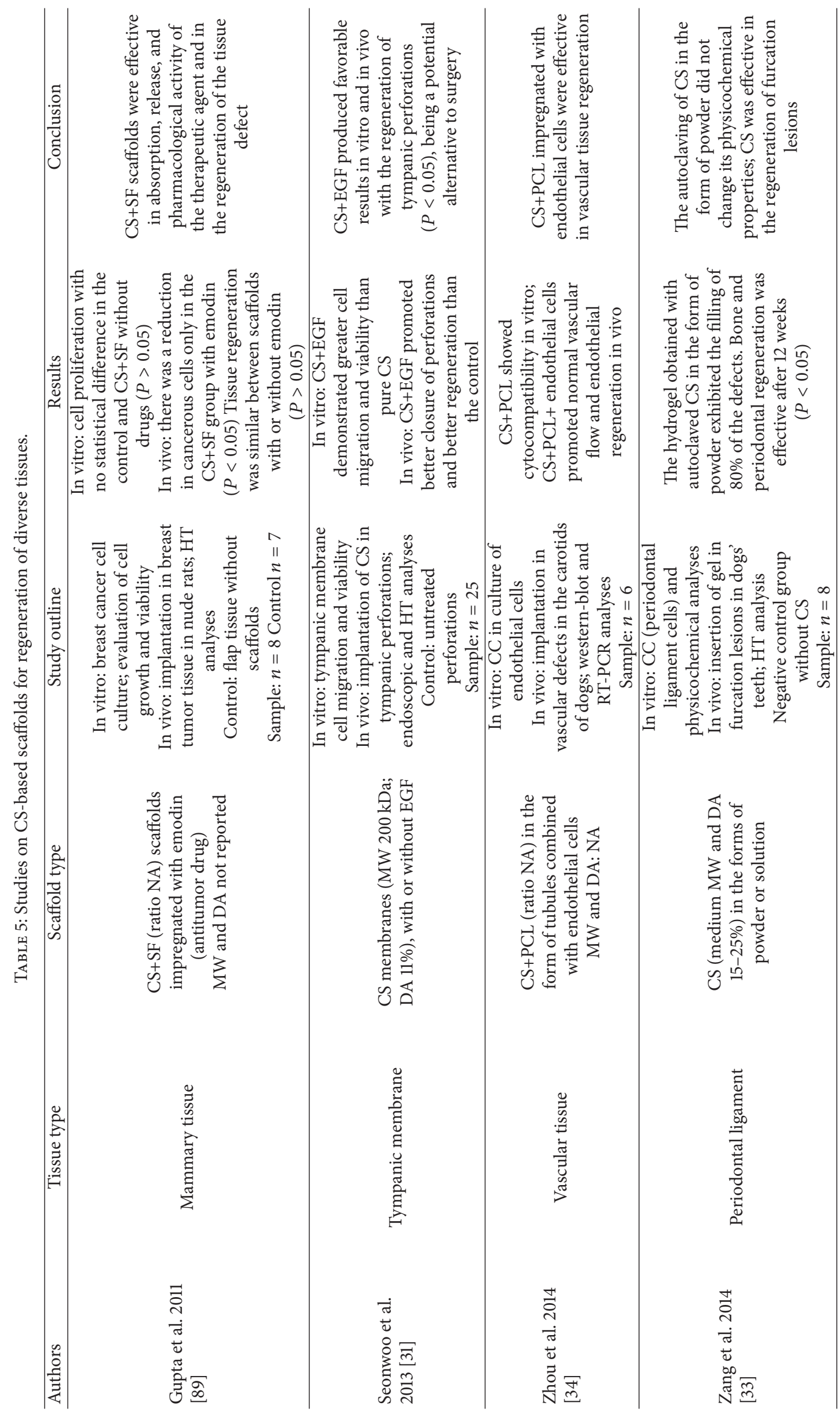




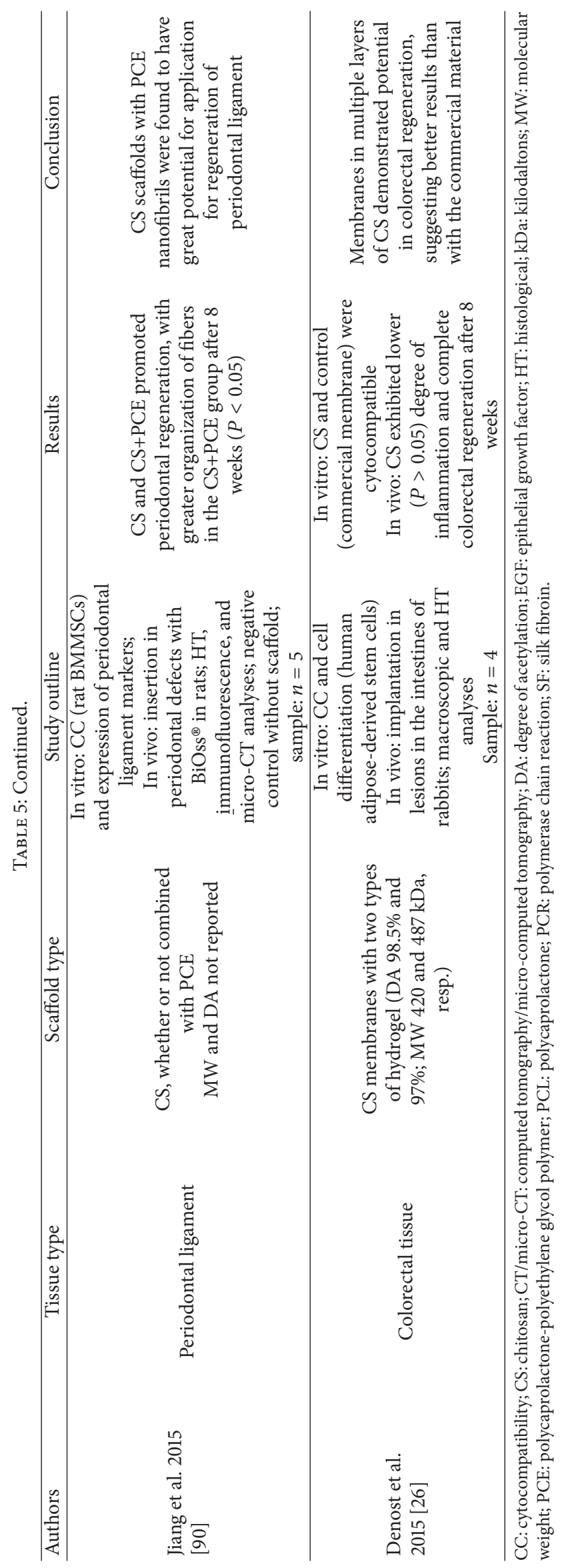


the substitution of its functional groups. The combination of CS with other natural polymers, such as collagen, gelatin, and silk fibroin, synthetic polymers such as PLGA, and compounds of calcium and phosphate, such as HA, permits an improvement in specific properties like solubility, biodegradation, and mechanical performance of CS as a function of the tissue to be regenerated [10]. In fact, some studies have clearly shown that the association of CS with collagen [42, $44,68]$, silk fibroin [73], and HA [45, 57, 58] was capable of promoting greater tissue regeneration than pure CS, as in these studies pure or combined CS scaffolds were implanted, making it possible to establish a comparison between them. However, in the vast majority of studies evaluating CS combined with other biomaterials, the favorable results obtained cannot be attributed to the associations, as pure CS was neither evaluated nor used as a control $[8,30,32,41,46,48$, $49,53,54,62,63,67,71,76,77,80,81,83,86,88]$.

Another aspect which merits some attention is the great variability in the chemical characteristics of CS used in the studies, such as molecular weight and degree of deacetylation. As it is a polymer which can be obtained from a variety of sources, CS may actually present a large variation in MW (ranging from 30 to $2000 \mathrm{kDa}$ ) and in $\mathrm{DA}$ (5 to $46 \%$ ) resulting from the different processing conditions [7, 21]. However, it should be stressed that these properties drive important physical characteristics of chitosan, such as solubility, crystallinity, absorption of water, and mechanical performance, and also biological characteristics, such as biodegradation, antimicrobial activity, mucoadhesiveness, and biocompatibility $[7,10,21,36,61]$. Wu et al. [38] and Zheng et al. [39], for instance, demonstrated that the in vitro bioactivity of CS on macrophages was dependant on its MW. Accordingly, it is probable that these parameters may influence the behavior of CS as a biomaterial for tissue regeneration. Thus, the use of such diverse chitosans, such as MW $22 \mathrm{kDa}$ [74] and $1800 \mathrm{kDa}$ [73], though both studies investigated regeneration in nerve tissue, renders any comparison of results unviable. In addition, the fact that MW and DA have not been specified in $47.5 \%$ of the studies raises speculation that the authors have overlooked the significance of these parameters. In fact, the lack of information on the physicochemical characteristics and their effects on biological properties of chitosan-based scaffolds is a matter of concern in the literature, since most of the useful applications of CS are determined by DA, MW, and the nature and fraction of substituents as pendant groups [19]. In the present review, only two studies accounted for the variation of MW in the methodology and interpretation of results. In the study by Cao et al. [49], chitosans of different molecular weights were evaluated in vitro and, based on the results, the $98 \mathrm{kDa}$ CS was selected for the in vivo assay. Denost et al. [26] used layers of CS of different MW to fabricate the scaffolds, due to the different characteristics they presented, corroborating the importance of this parameter on the biological activity of CS.

The use of comparison standards (control groups) is essential when investigating a particular experimental material. It is important to compare its effects with other already familiar or used materials (positive control) or with no treatment at all (negative control). In the present review, only $11.5 \%$ of the studies used positive and negative controls to compare with the experimental scaffolds $[30,33,48,73,76,77,80]$. As many as 20 studies (32.8\%) did not use negative controls for comparison. Bearing in mind that in some studies the results showed that tissue regeneration also occurred in negative control groups [31, 41, 48, 65], the absence of a negative control could cast doubt on the relevance of the results obtained with regard to the actual effectiveness of the material being investigated.

Sample size is an important consideration in the design of many studies because of its effect on statistical power. Statistical power is the probability that a statistical test will indicate a significant difference when there truly is one. In this review, some studies used small samples for their in vivo assays, with $n=3[32,46-48,61,65,68,81], n=2[27,56,69]$, and even $n=1$ [72]. It is important to point out that the value of $n$ considered in this study is always the number of animals used for each treatment condition. For instance, the study by Sundaramurthi et al. [65] mentions a sample of 30 animals. However, the animals were subdivided into 5 groups and 2 evaluation periods, totaling 10 groups, resulting in three animals for each condition evaluated $(n=3)$. Simões et al. [72] used 4 rats that were evaluated at 4 different points in time, resulting in just 1 animal per period $(n=1)$. Small samples, such as those mentioned in these studies, may compromise the results obtained, thus diminishing the reliability of the statistical differences found or omitting actual differences that could be observed with an increased sample size $[32,48,69]$. Given the importance of the sample size in the study outline and its influence on the results, it is significant to note that $16.4 \%$ of the studies reviewed do not clearly specify this information in their methodologies. The omission of this piece of information makes it difficult to interpret the results and establish a comparison between them.

The overall results concerning tissue regeneration with the use of CS-based scaffolds seem to indicate that they favored the regenerative in vivo process in $93.4 \%$ of the works reviewed. Although this information may suggest the effectiveness of CS, it is important to consider that quite a lot of the analysed studies used inadequate experimental designs (such as the absence of proper control groups, small sample size, and lack of comparisons between CS alone or combined with other biomaterials). For this reason, it is not possible to unequivocally confirm that the regeneration was due to the presence of chitosan. However, these results strongly suggest that CS fulfils the function of a scaffolding biomaterial as a reservoir of bioactive factors, such as stem cells and growth factors, showing biocompatibility, biodegradation, adsorption capacity, and gradual release of incorporated factors in most of the studies. Biological activity, with regard to the induction of tissue regeneration, seems to be attributed to the cell components and/or growth factors incorporated to the CS-based scaffolds and not to CS itself. In $83.33 \%$ of the studies in which scaffolds were compared, either with or without these components, the results showed a better regenerative performance with the presence of cells and/or growth factors. In other studies, there was no difference in results, neither with nor without bioactive factors $[29,56,80]$, or there was no comparison between them $[46,62,81]$. Therefore, it cannot 
be asserted, from the results presented, that chitosan possesses per se activity that induces tissue regeneration, as some authors suggest $[7,10,16,22,25]$. Nevertheless, some studies showed that pure CS, without the addition of bioactive factors, may be effective in promoting regeneration on cutaneous [64], nerve [79], colorectal [26], bone [55], periodontal ligament [33], and tympanic membrane [31] tissues.

\section{Conclusion}

The critical analysis of the studies reviewed confirms the potential for the application of chitosan as a biomaterial in tissue engineering, considering the great versatility of this polymer in the regeneration of various types of tissue in preclinical studies. Scaffolds composed of CS combined with other biomaterials, cells, and growth factors were found to be effective in promoting in vivo tissue regeneration. Nevertheless, the large chemical variability of the CS employed, the omission of precise information about its characteristics, and the methodological limitations of the studies make it difficult to reproduce and to establish a standardization for clinical application. Further studies are required with the aim of defining chitosan's ideal physicochemical characteristics for application with each type of tissue and, thus, propose a protocol for its use in clinical studies in order to confirm its effectiveness in tissue regeneration.

\section{Conflicts of Interest}

The authors declare that there are no conflicts of interest regarding the publication of this paper.

\section{Acknowledgments}

This work was supported by Brazilian government agencies: National Council of Scientific and Technological Development (CNPq) (Grants: Proc. no. 157763/2013-7) and Coordination for the Improvement of Higher Education Personnel (CAPES)/REUNI, Federal District, Brazil.

\section{References}

[1] R. Langer and J. P. Vacanti, “Tissue engineering," Science, vol. 260, no. 5110, pp. 920-926, 1993.

[2] R. Lanza, R. Langer, and J. Vacanti, Principles of Tissue Engineering, Elsevier, San Diego, Calif, USA, 2014.

[3] Q. Chen and G. A. Thouas, Biomaterials, A Basic Introduction, CRC Press, Boca Raton, USA, 2015.

[4] F. Schoen and R. Mitchel, "Tissues, the extracellular matrix and cell-biomaterial interactions," in Biomaterials Science: An Introduction to Materials in Medicine, B. Ratner, A. Hoffman, F. Schoen, and J. Lemons, Eds., pp. 260-281, Elsevier Academic Press, San Diego, Calif, USA, 2004.

[5] A. J. Salgado, O. P. Coutinho, and R. L. Reis, "Bone tissue engineering: state of the art and future trends," Macromolecular Bioscience, vol. 4, no. 8, pp. 743-765, 2004.

[6] S. Cartmell, "Controlled release scaffolds for bone tissue engineering," Journal of Pharmaceutical Sciences, vol. 98, no. 2, pp. 430-441, 2009.
[7] M. Rodríguez-Vázquez, B. Vega-Ruiz, R. Ramos-Zúñiga, D. A. Saldaña-Koppel, and L. F. Quiñones-Olvera, "Chitosan and its potential use as a scaffold for tissue engineering in regenerative medicine," BioMed Research International, vol. 2015, Article ID 821279, 15 pages, 2015.

[8] S. C. C. C. Miranda, G. A. B. Silva, R. C. R. Hell, M. D. Martins, J. B. Alves, and A. M. Goes, "Three-dimensional culture of rat BMMSCs in a porous chitosan-gelatin scaffold: a promising association for bone tissue engineering in oral reconstruction," Archives of Oral Biology, vol. 56, no. 1, pp. 1-15, 2011.

[9] T. J. Keane and S. F. Badylak, "Biomaterials for tissue engineering applications," Seminars in Pediatric Surgery, vol. 23, no. 3, pp. 112-118, 2014.

[10] I.-Y. Kim, S.-J. Seo, H.-S. Moon et al., "Chitosan and its derivatives for tissue engineering applications," Biotechnology Advances, vol. 26, no. 1, pp. 1-21, 2008.

[11] D. F. Williams, "On the nature of biomaterials," Biomaterials, vol. 30, no. 30, pp. 5897-5909, 2009.

[12] T. Dvir, B. P. Timko, D. S. Kohane, and R. Langer, "Nanotechnological strategies for engineering complex tissues," Nature Nanotechnology, vol. 6, no. 1, pp. 13-22, 2011.

[13] D. W. Hutmacher, "Scaffolds in tissue engineering bone and cartilage," Biomaterials, vol. 21, no. 24, pp. 2529-2543, 2000.

[14] K. F. Leong, C. M. Cheah, and C. K. Chua, "Solid freeform fabrication of three-dimensional scaffolds for engineering replacement tissues and organs," Biomaterials, vol. 24, no. 13, pp. 23632378, 2003.

[15] B. Dhandayuthapani, Y. Yoshida, T. Maekawa, and D. S. Kumar, "Polymeric scaffolds in tissue engineering application: a review," International Journal of Polymer Science, vol. 2011, Article ID 290602, 19 pages, 2011.

[16] M. Rinaudo, "Chitin and chitosan: properties and applications," Progress in Polymer Science (Oxford), vol. 31, no. 7, pp. 603-632, 2006.

[17] P. Baldrick, "The safety of chitosan as a pharmaceutical excipient," Regulatory Toxicology and Pharmacology, vol. 56, no. 3, pp. 290-299, 2010.

[18] R. A. A. Muzzarelli, "Chitins and chitosans for the repair of wounded skin, nerve, cartilage and bone," Carbohydrate Polymers, vol. 76, no. 2, pp. 167-182, 2009.

[19] B. Bellich, I. D’Agostino, S. Semeraro, A. Gamini, and A. Cesàro, "The good, the bad and the ugly of chitosans," Marine Drugs, vol. 14, no. 5, article 99, 2016.

[20] C. Peniche, M. Fernández, G. Rodríguez et al., "Cell supports of chitosan/hyaluronic acid and chondroitin sulphate systems. Morphology and biological behaviour," Journal of Materials Science: Materials in Medicine, vol. 18, no. 9, pp. 1719-1726, 2007.

[21] T. W. Wong, "Chitosan and its use in design of insulin delivery system," Recent Patents on Drug Delivery \& Formulation, vol. 3, no. 1 , pp. 8-25, 2009.

[22] I. A. Sogias, A. C. Williams, and V. V. Khutoryanskiy, "Why is chitosan mucoadhesive?" Biomacromolecules, vol. 9, no. 7, pp. 1837-1842, 2008

[23] S. V. Madihally and H. W. T. Matthew, "Porous chitosan scaffolds for tissue engineering," Biomaterials, vol. 20, no. 12, pp. 1133-1142, 1999.

[24] R. Zeinali, E. Biazar, S. H. Keshel, M. R. Tavirani, and K. Asadipour, "Regeneration of full-thickness skin defects using umbilical cord blood stem cells loaded into modified porous scaffolds," ASAIO Journal, vol. 60, no. 1, pp. 106-114, 2014. 
[25] S. Rodrigues, M. Dionísio, C. R. López, and A. Grenha, "Biocompatibility of chitosan carriers with application in drug delivery," Journal of Functional Biomaterials, vol. 3, no. 4, pp. 615-641, 2012.

[26] Q. Denost, J.-P. Adam, A. Pontallier et al., "Colorectal tissue engineering: a comparative study between porcine small intestinal submucosa (SIS) and chitosan hydrogel patches," Surgery, vol. 158, no. 6, pp. 1714-1723, 2015.

[27] F. Han, Y. Dong, Z. Su, R. Yin, A. Song, and S. Li, "Preparation, characteristics and assessment of a novel gelatin-chitosan sponge scaffold as skin tissue engineering material," International Journal of Pharmaceutics, vol. 476, no. 1, pp. 124-133, 2014.

[28] S. Jia, X. Yang, W. Song et al., "Incorporation of osteogenic and angiogenic small interfering RNAs into chitosan sponge for bone tissue engineering," International journal of nanomedicine, vol. 9, pp. 5307-5316, 2014.

[29] D. Revi, W. Paul, T. V. Anilkumar, and C. P. Sharma, "Chitosan scaffold co-cultured with keratinocyte and fibroblast heals full thickness skin wounds in rabbit," Journal of Biomedical Materials Research-Part A, vol. 102, no. 9, pp. 3273-3281, 2014.

[30] Y. Gu, J. Zhu, C. Xue et al., "Chitosan/silk fibroin-based, Schwann cell-derived extracellular matrix-modified scaffolds for bridging rat sciatic nerve gaps," Biomaterials, vol. 35, no. 7, pp. 2253-2263, 2014.

[31] H. Seonwoo, S. W. Kim, J. Kim et al., "Regeneration of chronic tympanic membrane perforation using an EGF-releasing chitosan patch," Tissue Engineering-Part A, vol. 19, no. 17-18, pp. 2097-2107, 2013.

[32] Y. Cheng, P. Cheng, F. Xue et al., "Repair of ear cartilage defects with allogenic bone marrow mesenchymal stem cells in rabbits," Cell Biochemistry and Biophysics, vol. 70, no. 2, pp. 1137-1143, 2014.

[33] S. Zang, G. Dong, B. Peng et al., "A comparison of physicochemical properties of sterilized chitosan hydrogel and its applicability in a canine model of periodontal regeneration," Carbohydrate Polymers, vol. 113, pp. 240-248, 2014.

[34] M. Zhou, W. Qiao, Z. Liu et al., "Development and in vivo evaluation of small-diameter vascular grafts engineered by outgrowth endothelial cells and electrospun chitosan/poly $(\varepsilon-$ caprolactone) Nanofibrous Scaffolds," Tissue Engineering - Part A, vol. 20, no. 1-2, pp. 79-91, 2014.

[35] T. Kean and M. Thanou, "Biodegradation, biodistribution and toxicity of chitosan," Advanced Drug Delivery Reviews, vol. 62, no. 1, pp. 3-11, 2010.

[36] I. Younes and M. Rinaudo, "Chitin and chitosan preparation from marine sources. Structure, properties and applications," Marine Drugs, vol. 13, no. 3, pp. 1133-1174, 2015.

[37] W. Suphasiriroj, P. Yotnuengnit, R. Surarit, and R. Pichyangkura, "The fundamental parameters of chitosan in polymer scaffolds affecting osteoblasts (MC3T3-E1)," Journal of Materials Science: Materials in Medicine, vol. 20, no. 1, pp. 309-320, 2009.

[38] N. Wu, Z.-S. Wen, X.-W. Xiang et al., "Immunostimulative activity of low molecular weight chitosans in RAW264.7 macrophages," Marine Drugs, vol. 13, no. 10, pp. 6210-6225, 2015.

[39] B. Zheng, Z. S. Wen, Y. J. Huang, M. S. Xia, X. W. Xiang, and Y. L. $\mathrm{Qu}$, "Molecular weight-dependent immunostimulative activity of low molecular weight chitosan via regulating NF- $\kappa$ B and AP-1 signaling pathways in RAW264.7 macrophages," Marine Drugs, vol. 14, no. 10, p. 169, 2016.

[40] C. Tangsadthakun, S. Kanokpanont, N. Sanchavanakit et al., "The influence of molecular weight of chitosan on the physical and biological properties of collagen/chitosan scaffolds," Journal of Biomaterials Science, Polymer Edition, vol. 18, no. 2, pp. 147163, 2007.

[41] S. N. Danilchenko, O. V. Kalinkevich, M. V. Pogorelov et al., "Characterization and in vivo evaluation of chitosan-hydroxyapatite bone scaffolds made by one step coprecipitation method," Journal of Biomedical Materials Research-Part A, vol. 96, no. 4, pp. 639-647, 2011.

[42] X. Niu, Y. Fan, X. Liu et al., "Repair of bone defect in femoral condyle using microencapsulated chitosan, nanohydroxyapatite/collagen and poly(l-lactide)-based microsphere-scaffold delivery system," Artificial Organs, vol. 35, no. 7, pp. E119-E128, 2011.

[43] A. R. Costa-Pinto, V. M. Correlo, P. C. Sol et al., "Chitosanpoly(butylene succinate) scaffolds and human bone marrow stromal cells induce bone repair in a mouse calvaria model," Journal of Tissue Engineering and Regenerative Medicine, vol. 6, no. 1, pp. 21-28, 2012.

[44] J. Hou, J. Wang, L. Cao et al., "Segmental bone regeneration using rhBMP-2-loaded collagen/chitosan microspheres composite scaffold in a rabbit model," Biomedical Materials, vol. 7, no. 3, Article ID 035002, 2012.

[45] X. Zhang, L. Zhu, H. Lv et al., "Repair of rabbit femoral condyle bone defects with injectable nanohydroxyapatite/chitosan composites," Journal of Materials Science: Materials in Medicine, vol. 23, no. 8, pp. 1941-1949, 2012.

[46] S. C. C. C. Miranda, G. A. B. Silva, R. M. Mendes et al., "Mesenchymal stem cells associated with porous chitosan-gelatin scaffold: a potential strategy for alveolar bone regeneration," Journal of Biomedical Materials Research-Part A, vol. 100, no. 10, pp. 2775-2786, 2012.

[47] S. J. Florczyk, M. Leung, Z. Li, J. I. Huang, R. A. Hopper, and M. Zhang, "Evaluation of three-dimensional porous chitosanalginate scaffolds in rat calvarial defects for bone regeneration applications," Journal of Biomedical Materials Research-Part A, vol. 101, no. 10, pp. 2974-2983, 2013.

[48] H. Jiang, Y. Zuo, Q. Zou et al., "Biomimetic spiral-cylindrical scaffold based on hybrid chitosan/cellulose/nano-hydroxyapatite membrane for bone regeneration," ACS Applied Materials \& Interfaces, vol. 5, no. 22, pp. 12036-12044, 2013.

[49] L. Cao, J. Wang, J. Hou, W. Xing, and C. Liu, "Vascularization and bone regeneration in a critical sized defect using 2N,6-O-sulfated chitosan nanoparticles incorporating BMP-2," Biomaterials, vol. 35, no. 2, pp. 684-698, 2014.

[50] J. S. Lee, S. D. Baek, J. Venkatesan et al., "In vivo study of chitosan-natural nano hydroxyapatite scaffolds for bone tissue regeneration," International Journal of Biological Macromolecules, vol. 67, pp. 360-366, 2014.

[51] T. Fernández, G. Olave, C. H. Valencia et al., "Effects of calcium phosphate/chitosan composite on bone healing in rats: calcium phosphate induces osteon formation," Tissue Engineering-Part A, vol. 20, no. 13-14, pp. 1948-1960, 2014.

[52] J. Fan, H. Park, M. K. Lee et al., "Adipose-derived stem cells and BMP-2 delivery in chitosan-based 3D constructs to enhance bone regeneration in a rat mandibular defect model," Tissue Engineering-Part A, vol. 20, no. 15-16, pp. 2169-2179, 2014.

[53] A. Koç, G. Finkenzeller, A. E. Elçin, G. B. Stark, and Y. M. Elçin, "Evaluation of adenoviral vascular endothelial growth factoractivated chitosan/hydroxyapatite scaffold for engineering vascularized bone tissue using human osteoblasts: in vitro and in vivo studies," Journal of Biomaterials Applications, vol. 29, no. 5, pp. 748-760, 2014. 
[54] G.-J. Lai, K. T. Shalumon, and J.-P. Chen, "Response of human mesenchymal stem cells to intrafibrillar nanohydroxyapatite content and extrafibrillar nanohydroxyapatite in biomimetic chitosan/silk fibroin/nanohydroxyapatite nanofibrous membrane scaffolds," International Journal of Nanomedicine, vol. 10, pp. 567-584, 2015.

[55] P. Ghosh, A. P. Rameshbabu, D. Das et al., "Covalent cross-links in polyampholytic chitosan fibers enhances bone regeneration in a rabbit model," Colloids and Surfaces B: Biointerfaces, vol. 125, pp. 160-169, 2015.

[56] S. G. Caridade, C. Monge, J. Almodóvar et al., "Myoconductive and osteoinductive free-standing polysaccharide membranes," Acta Biomaterialia, vol. 15, pp. 139-149, 2015.

[57] M. E. Frohbergh, A. Katsman, M. J. Mondrinos et al., "Osseointegrative properties of electrospun hydroxyapatite-containing nanofibrous chitosan scaffolds," Tissue Engineering_Part A, vol. 21, no. 5-6, pp. 970-981, 2015.

[58] S. Dhivya, S. Saravanan, T. P. Sastry, and N. Selvamurugan, "Nanohydroxyapatite-reinforced chitosan composite hydrogel for bone tissue repair in vitro and in vivo," Journal of Nanobiotechnology, vol. 13, no. 1, article 40, 2015.

[59] S. D’Mello, S. Elangovan, L. Hong, R. D. Ross, D. R. Sumner, and A. K. Salem, "Incorporation of copper into chitosan scaffolds promotes bone regeneration in rat calvarial defects," Journal of Biomedical Materials Research-Part B Applied Biomaterials, vol. 103, no. 5, pp. 1044-1049, 2015.

[60] J. Ji, X. Tong, X. Huang et al., "Sphere-shaped nano-hydroxyapatite/chitosan/gelatin 3D porous scaffolds increase proliferation and osteogenic differentiation of human induced pluripotent stem cells from gingival fibroblasts," Biomedical Materials (Bristol), vol. 10, no. 4, Article ID 045005, 2015.

[61] K. T. Shalumon, G.-J. Lai, C.-H. Chen, and J.-P. Chen, "Modulation of bone-specific tissue regeneration by incorporating bone morphogenetic protein and controlling the shell thickness of silk fibroin/chitosan/nanohydroxyapatite core-shell nanofibrous membranes," ACS Applied Materials \& Interfaces, vol. 7, no. 38, pp. 21170-21181, 2015.

[62] J. Xie, C. Peng, Q. Zhao et al., "Osteogenic differentiation and bone regeneration of iPSC-MSCs supported by a biomimetic nanofibrous scaffold," Acta Biomaterialia, vol. 29, pp. 365-379, 2016.

[63] R. Guo, S. Xu, L. Ma, A. Huang, and C. Gao, “The healing of full-thickness burns treated by using plasmid DNA encoding VEGF-165 activated collagen-chitosan dermal equivalents," Biomaterials, vol. 32, no. 4, pp. 1019-1031, 2011.

[64] V. T. Tchemtchoua, G. Atanasova, A. Aqil et al., "Development of a Chitosan Nanofibrillar Scaffold for Skin Repair and Regeneration," Biomacromolecules, vol. 12, no. 9, pp. 3194-3204, 2011.

[65] D. Sundaramurthi, K. S. Vasanthan, P. Kuppan, U. M. Krishnan, and S. Sethuraman, "Electrospun nanostructured chitosanpoly(vinyl alcohol) scaffolds: a biomimetic extracellular matrix as dermal substitute," Biomedical Materials, vol. 7, no. 4, Article ID 045005, 2012.

[66] B. Veleirinho, D. S. Coelho, P. F. Dias, M. Maraschin, R. M. Ribeiro-do-Valle, and J. A. Lopes-da-Silva, "Nanofibrous poly(3-hydroxybutyrate-co-3-hydroxyvalerate)/chitosan scaffolds for skin regeneration," International Journal of Biological Macromolecules, vol. 51, no. 4, pp. 343-350, 2012.

[67] X. Wang, C. You, X. Hu et al., "The roles of knitted meshreinforced collagen-chitosan hybrid scaffold in the one-step repair of full-thickness skin defects in rats," Acta Biomaterialia, vol. 9, no. 8, pp. 7822-7832, 2013.
[68] S. D. Sarkar, B. L. Farrugia, T. R. Dargaville, and S. Dhara, "Chitosan-collagen scaffolds with nano/microfibrous architecture for skin tissue engineering," Journal of Biomedical Materials Research-Part A, vol. 101, no. 12, pp. 3482-3492, 2013.

[69] R. Guo, J. Teng, S. Xu, L. Ma, A. Huang, and C. Gao, “Comparison studies of the in vivo treatment of full-thickness excisional wounds and burns by an artificial bilayer dermal equivalent and J-1 acellular dermal matrix," Wound Repair and Regeneration, vol. 22, no. 3, pp. 390-398, 2014.

[70] M. I. N. Ahamed, S. Sankar, P. M. Kashif, S. K. H. Basha, and T. P. Sastry, "Evaluation of biomaterial containing regenerated cellulose and chitosan incorporated with silver nanoparticles," International Journal of Biological Macromolecules, vol. 72, pp. 680-686, 2015.

[71] X. Wang, P. Wu, X. Hu et al., "Polyurethane membrane/knitted mesh-reinforced collagen-chitosan bilayer dermal substitute for the repair of full-thickness skin defects via a two-step procedure," Journal of the Mechanical Behavior of Biomedical Materials, vol. 56, pp. 120-133, 2016.

[72] M. J. Simões, A. Gartner, Y. Shirosaki et al., "In vitro and in vivo chitosan membranes testing for peripheral nerve reconstruction," Acta Medica Portuguesa, vol. 24, pp. 43-52, 2011.

[73] Y. Wei, K. Gong, Z. Zheng et al., "Chitosan/silk fibroin-based tissue-engineered graft seeded with adipose-derived stem cells enhances nerve regeneration in a rat model," Journal of Materials Science: Materials in Medicine, vol. 22, no. 8, pp. 1947-1964, 2011.

[74] X. Chen, Y. Yang, J. Yao et al., "Bone marrow stromal cellsloaded chitosan conduits promote repair of complete transection injury in rat spinal cord," Journal of Materials Science: Materials in Medicine, vol. 22, no. 10, pp. 2347-2356, 2011.

[75] C.-D. Liao, F. Zhang, R.-M. Guo et al., "Peripheral nerve repair: Monitoring by using gadofluorine M-enhanced MR imaging with chitosan nerve conduits with cultured mesenchymal stem cells in rat model of neurotmesis," Radiology, vol. 262, no. 1, pp. 161-171, 2012.

[76] C. Xue, N. Hu, Y. Gu et al., "Joint use of a chitosan/PLGA scaffold and MSCs to bridge an extra large gap in dog sciatic nerve," Neurorehabilitation and Neural Repair, vol. 26, no. 1, pp. 96-106, 2012.

[77] W. Xiao, X. Y. Hu, W. Zeng, J. H. Huang, Y. G. Zhang, and Z. J. Luo, "Rapid sciatic nerve regeneration of rats by a surface modified collagen-chitosan scaffold," Injury, vol. 44, no. 7, pp. 941-946, 2013.

[78] E. Biazar and S. H. Keshel, "Chitosan-cross-linked nanofibrous PHBV nerve guide for rat sciatic nerve regeneration across a defect bridge," ASAIO Journal, vol. 59, no. 6, pp. 651-659, 2013.

[79] Y. Wang, Y. Zhao, C. Sun et al., "Chitosan Degradation Products Promote Nerve Regeneration by Stimulating Schwann Cell Proliferation via miR-27a/FOXO1 Axis," Molecular Neurobiology, vol. 53, no. 1, pp. 28-39, 2016.

[80] J. Chen, H. Chen, P. Li et al., "Simultaneous regeneration of articular cartilage and subchondral bone in vivo using MSCs induced by a spatially controlled gene delivery system in bilayered integrated scaffolds," Biomaterials, vol. 32, no. 21, pp. 4793-4805, 2011.

[81] S. W. Whu, K. C. Hung, K. H. Hsieh, C. H. Chen, C. L. Tsai, and S. H. Hsu, "In vitro and in vivo evaluation of chitosan-gelatin scaffolds for cartilage tissue engineering," Materials Science and Engineering C, Materials for Biological Applications, vol. 33, pp. 2855-2863, 2013. 
[82] K. Zhang, Y. Zhang, S. Yan et al., "Repair of an articular cartilage defect using adipose-derived stem cells loaded on a polyelectrolyte complex scaffold based on poly(l-glutamic acid) and chitosan," Acta Biomaterialia, vol. 9, no. 7, pp. 7276-7288, 2013.

[83] J. Deng, R. She, W. Huang, Z. Dong, G. Mo, and B. Liu, "A silk fibroin/chitosan scaffold in combination with bone marrowderived mesenchymal stem cells to repair cartilage defects in the rabbit knee," Journal of Materials Science: Materials in Medicine, vol. 24, no. 8, pp. 2037-2046, 2013.

[84] Y. Wu, Z. Gong, J. Li, Q. Meng, W. Fang, and X. Long, "The pilot study of fibrin with temporomandibular joint derived synovial stem cells in repairing TMJ disc perforation," BioMed Research International, vol. 2014, Article ID 454021, 10 pages, 2014.

[85] F. Ravanetti, C. Galli, E. Manfredi et al., "Chitosan-based scaffold modified with D-(+) raffinose for cartilage repair: an in vivo study," Journal of Negative Results in BioMedicine, vol. 14, no. 1, article 2, p. 2, 2015.

[86] S. Ravindran, M. Kotecha, C.-C. Huang et al., "Biological and MRI characterization of biomimetic ECM scaffolds for cartilage tissue regeneration," Biomaterials, vol. 71, Article ID 17025, pp. 58-70, 2015.

[87] Q. Meng, Z. Man, L. Dai et al., "A composite scaffold of MSC affinity peptide-modified demineralized bone matrix particles and chitosan hydrogel for cartilage regeneration," Scientific Reports, vol. 5, Article ID 17802, 2015.

[88] K. Zhang, S. Yan, G. Li, L. Cui, and J. Yin, "In-situ birth of MSCs multicellular spheroids in poly(L-glutamic acid)/chitosan scaffold for hyaline-like cartilage regeneration," Biomaterials, vol. 71, pp. 24-34, 2015.

[89] V. Gupta, G.-H. Mun, B. Choi et al., "Repair and reconstruction of a resected tumor defect using a composite of tissue flapnanotherapeutic-silk fibroin and chitosan scaffold," Annals of Biomedical Engineering, vol. 39, no. 9, pp. 2374-2387, 2011.

[90] W. Jiang, L. Li, D. Zhang et al., "Incorporation of aligned PCLPEG nanofibers into porous chitosan scaffolds improved the orientation of collagen fibers in regenerated periodontium," Acta Biomaterialia, vol. 25, pp. 240-252, 2015. 


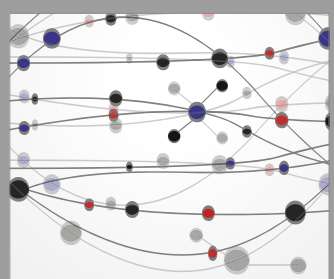

The Scientific World Journal
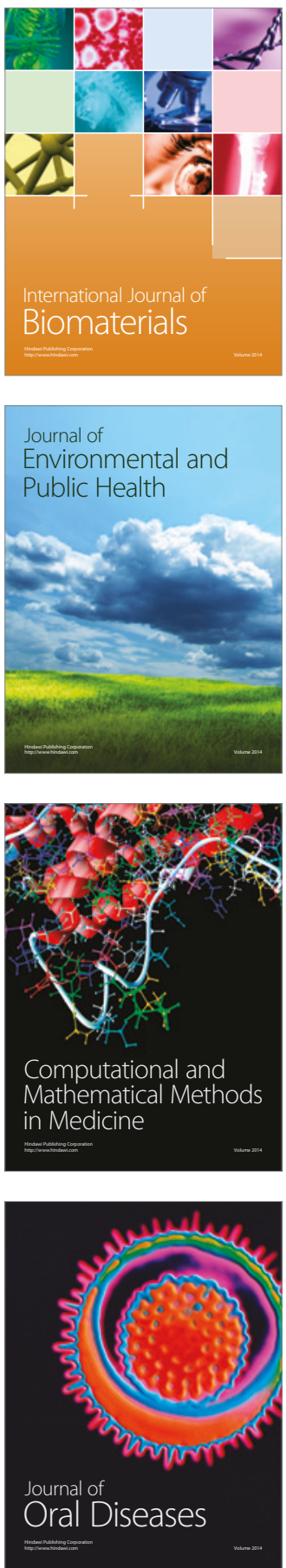
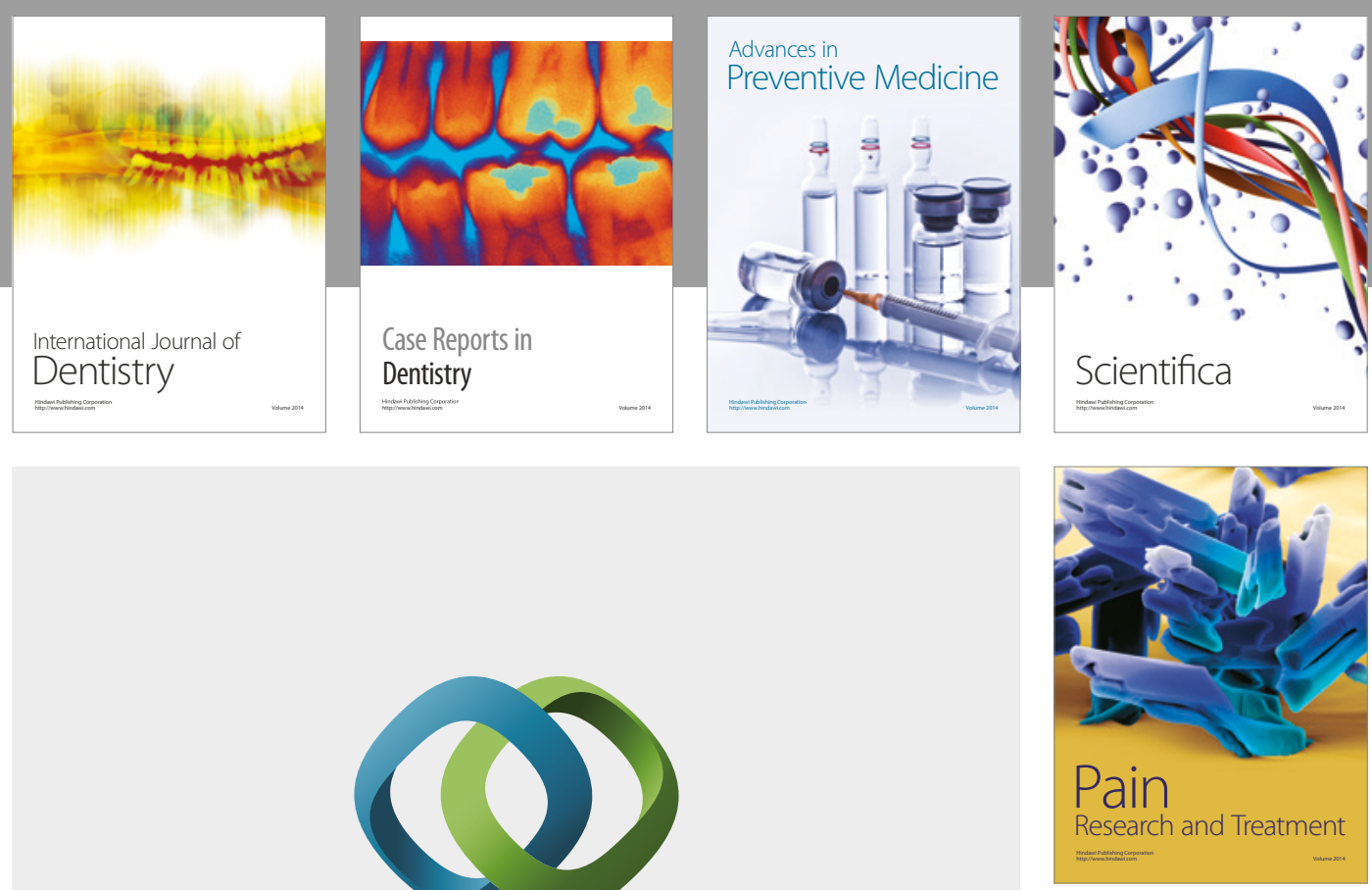

\section{Hindawi}

Submit your manuscripts at

https://www.hindawi.com
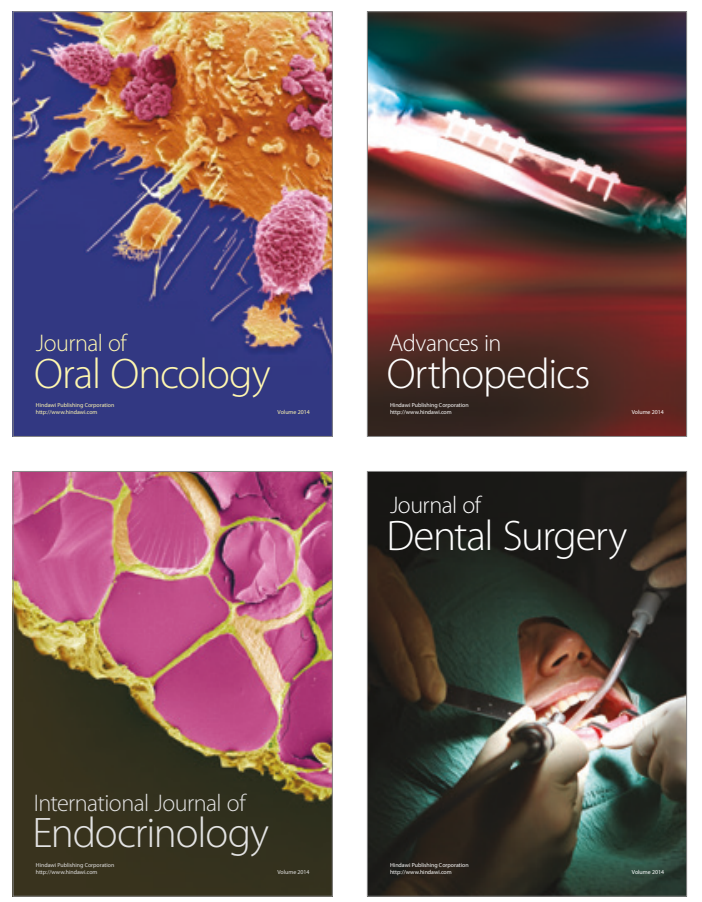
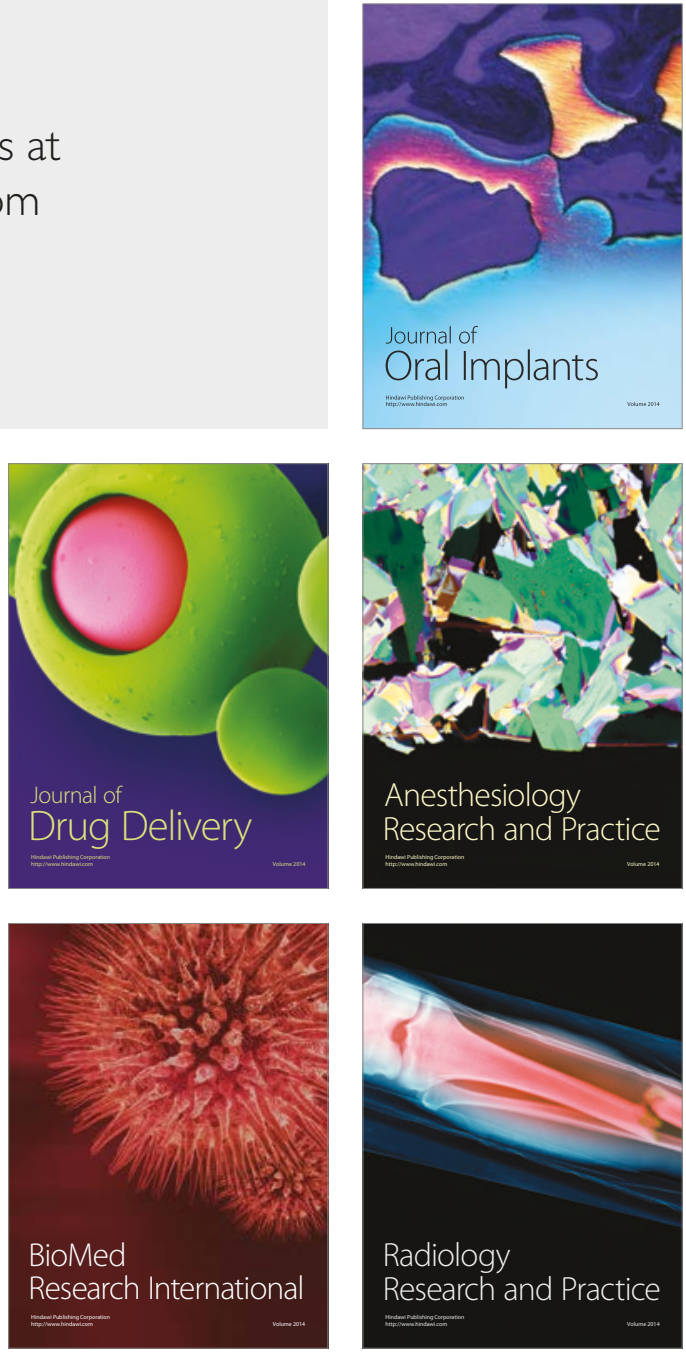